Discussion

Papers

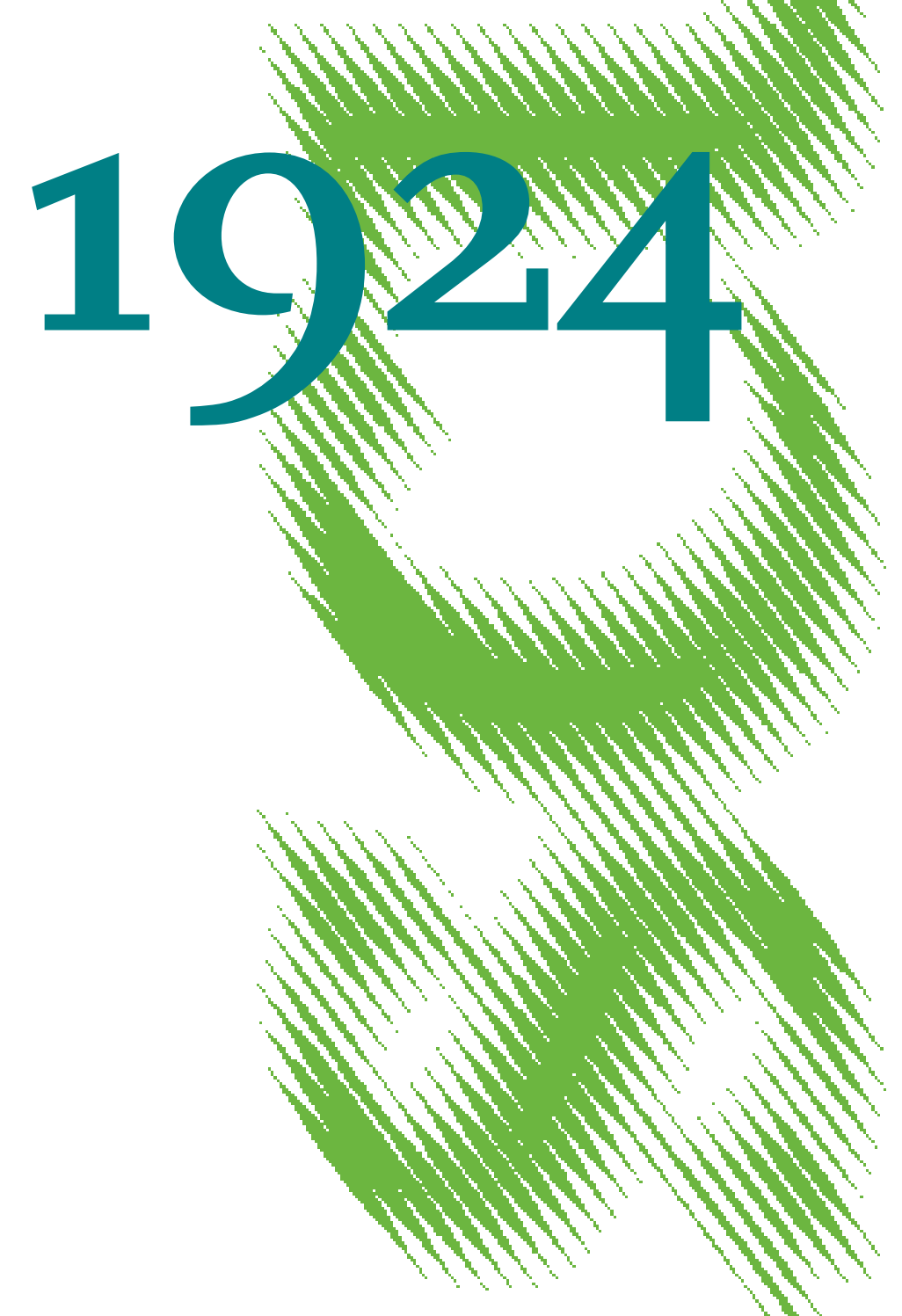

Emergency Aid for Self-Employed in the COVID-19 Pandemic: A Flash in the Pan? 
Opinions expressed in this paper are those of the author(s) and do not necessarily reflect views of the institute.

IMPRESSUM

(C) DIW Berlin, 2020

DIW Berlin

German Institute for Economic Research

Mohrenstr. 58

10117 Berlin

Tel. +49 (30) $89789-0$

Fax +49 (30) $89789-200$

http://www.diw.de

ISSN electronic edition 1619-4535

Papers can be downloaded free of charge from the DIW Berlin website:

http://www.diw.de/discussionpapers

Discussion Papers of DIW Berlin are indexed in RePEc and SSRN:

http://ideas.repec.org/s/diw/diwwpp.html

http://www.ssrn.com/link/DIW-Berlin-German-Inst-Econ-Res.html 


\title{
Emergency Aid for Self-employed in the COVID-19 pandemic: A Flash in the Pan?*
}

\author{
Joern Block ${ }^{\dagger}$ \\ Trier University \\ Alexander Kritikos ${ }^{\sharp}$ \\ DIW Berlin \\ Maximilian Priem ${ }^{\S}$ \\ Maximilian Priem
DIW Econ \\ Caroline Stiel** \\ DIW Berlin
}

December, 2020

\begin{abstract}
:
The self-employed are among those facing the highest probability of strong income losses during the COVID-19 pandemic. Governments in many countries introduced support programs to support the self-employed, including the German federal government, which approved a €50bn emergency aid program at the end of March 2020 offering one-off lump-sum payments of up to $€ 15,000$ to those facing substantial revenue declines. In this contribution, we investigate the impact of this program using a real-time online-survey data with a total of more than 20,000 observations. We employ propensity score matching, making use of a rich set of variables that influence selection into the treatment and the outcome variable, the subjective survival probability. We observe that the emergency aid program had significant effects, with the subjective survival probability of self-employment being moderately increased. We further reveal important effect heterogeneities with respect to education, risk tolerance, and industries. We also observe positive effects only among those whose application was processed within a few days. Lastly, the positive effect on the survival probability is fading out already two weeks after the emergency aid was granted. Our findings have important policy implications for the design of such support programs in the course of this crisis.
\end{abstract}

JEL Classification: C14, H43, L25, L26, J68

Keywords: Self-Employment, Emergency Aid, Treatment Effects, COVID-19, Entrepreneurship

We gratefully acknowledge the support of Thea Zöllner and the Verband der Gründer und Selbstständigen Deutschland e. V. (VGSD) who provided us with the data. Moreover, we thank Daniel Graeber, Steffen Künn, and Johannes Seebauer for the valuable comments.

$\dagger$ Joern Block is Professor at the University of Trier, the Department of Applied Economics, Erasmus University Rotterdam, and Wittener Institut für Familienunternehmen (WIFU), University of Witten/Herdecke. e-mail: block@uni-trier.de.

* Alexander Kritikos, (corresponding author is Research Director at the German Institute for Economic Research (DIW Berlin), Professor of Economics at the University of Potsdam, and Research Fellow at IZA, Bonn and at IAB, Nuremberg. Address: DIW Berlin, Mohrenstr. 58, 10117 Berlin, Germany. email: akritikos@diw.de

$\S$ Maximilian Priem is Senior Data Scientist at DIW Econ., e-mail: MPriem@diw-econ.de

** Caroline Stiel is Senior Research Associate at the German Institute for Economic Research (DIW Berlin), e-mail: cstiel@diw.de 


\section{Introduction}

The unprecedented shutdown of businesses, especially of those in the service sector and the trade industries, as well as general insecurity, has led in many countries to a temporary closure of major parts of their economies in spring 2020. The affected industries depend more on the self-employed and micro businesses (collectively referred to as "selfemployed" from now on) than the manufacturing sector. First evidence points to the fact that the self-employed population has suffered more strongly from the disruption caused by the COVID-19 pandemic than other parts of the working population in relative terms. In Germany, for instance, about $60 \%$ of the self-employed faced sales and income losses, while only about $15 \%$ of dependently employed individuals confronted job or wage losses (see Kritikos et al. 2020). ${ }^{1}$ Therefore, in addition to Kurzarbeit, Germany's short time work compensation scheme that is a well-established safety net for employees (see Cahuc 2014), the German government introduced at the end of March 2020 an emergency aid program designed to financially support those self-employed who faced strong revenue declines. The main aim of this paper is to investigate the effects of this program on the subjective survival probability among the supported self-employed.

In Germany, around 4.2 million individuals (about $10 \%$ of the working population) are self-employed, either without any employees (so called solo self-employed, see e.g. de Vries et al. 2019) and sometimes with hourly earnings around the minimum wage (Sorgner et al. 2017) or with employees, often running micro businesses with fewer than 10 employees (hereafter "employers"). This diverse population of self-employed, which has grown strongly since the 1990s, is an increasingly important part of the German economy, from both labor market and economic perspectives. This role is not limited to creating their own and other jobs. In several parts of the service sector, such ventures are the backbone of the economy, where the largest share of individuals are employed in firms with 10 or fewer employees (Audretsch et al. 2020). Given the relevance of the sum of all selfemployed workers (solo self-employed and employers) for the German economy and given that a large share of them is facing strong revenue declines and income losses during the COVID-19 pandemic, their survival and ongoing struggles in the pandemic are of high concern for policy makers.

\footnotetext{
${ }^{1}$ See Crossley et al. (2021) for other employment groups that were also severely affected by this crisis.
} 
In response to the crisis, the German Minister of Economics Affairs announced at a press conference on March 10, 2020, "that we will not let any firm down" ${ }^{2}$. His ministry introduced together with the Ministry of Finance an extensive emergency aid program ("Soforthilfe") of up to $€ 50$ billion to support the self-employed (including micro firms with up to 10 employees). The program took the form of a one-off lump sum grant of up to $€ 15,000$ per self-employed, that could be paid out of this program and was accessible between the end of March and end of May 2020. $€ 13.7$ billion of the $€ 50$ billion were spent through this program. In this contribution, we investigate whether the program achieved to increase the subjective probability of the affected self-employed to get through the COVID19 pandemic. This research question is particularly relevant given the huge amount of taxpayer money that was made available for this program. ${ }^{3}$

For our analysis, we rely on a survey that was answered by more than 20,000 selfemployed and that took place in April and early May 2020. Besides information on crisis related sales losses, resulting liquidity constraints, the willingness to apply for financial support from the emergency fund as well as on information whether financial support was actually received, the survey recorded information on most individual- and firm-related characteristics that are known to be relevant for self-employment activities. As outcome variable, we focus on a measure that is based on the subjective assessment of the individuals about the probability that they have to "end their self-employment activities due to the Corona-crisis in the following 12 months". Prior research (Cassar 2010, Hyytinen et al. 2014) has used such subjective survival probability measures and has shown its correlation with objective survival measures and relevance in entrepreneurial decisionmaking. Moreover, beyond the rich information on the self-employed, we make use of the fact that the data is surveyed in real-time recording the exact days of the respondent's emergency aid application as well as its approval or denial.

To be able to causally analyze whether the financial support measures increased the subjective survival probability, we rely on the conditional independence assumption (CIA). More specifically, we compare those self-employed who already received support out of this program (the treated group) with those who planned to apply for the program (the untreated group), controlling for a rich set of variables that influence the application and

2 Press conference of the Minister of Economics at March 10, 2020 (see (https://www.tagesschau.de/inland/corona-wirtschaft-105.html, accessed November 27, 2020).

3 In order to classify the budget of the program of $€ 50 \mathrm{bn}$, we point to typical measures in the area of selfemployment, for instance the various start-up subsidy programs in Germany that received yearly budgets of less than $€ 1$ bn (with the exception of the year 2004, when it reached $€ 2$ bn). For an evaluation of these subsidies, see inter alia Caliendo and Kuenn (2011). 
survival probability. This includes also information on how severely they were hit by the crisis and for how long they had liquidity reserves to survive the crisis.

We contribute to the literature around the analysis of the COVID-19 pandemic (Adams-Prassl et al. 2020, Block et al. 2020, Blundell and Machin 2020, Fairlie 2020, Graeber et al. 2020) in several ways. This crisis is unique in itself and there is, so far, no experience how public interventions that aim to deal with the economic consequences of the crisis, may help. It might also not be possible to infer insights from analyzing public policies that were taken in earlier crisis situations like the financial crisis from 2008, as the causes of the financial crisis strongly differ from the current one. In that context, we provide first empirical evidence on the subjectively perceived effectiveness of an emergency aid program during this pandemic. Secondly, we take advantage of real-time, individual-level data that allow us to investigate the impact of variations in the speed of processing the applications for emergency aid. Thirdly, we analyze effect heterogeneities with respect to various variables, such as risk tolerance or education levels. In that sense, our analysis is of high relevance given the ongoing debate on the right design and implementation of such policy instruments, informing about which specific target groups perceive the public financial support positively under the given conditions. With our results, we also contribute to the literature on small business policy (Minniti 2008, Acs et al. 2016) in times of economic crises, as well as on the effects of entrepreneurial optimism and subjective survival probability (Cassar 2010, Hytytinen et al. 2014).

Based on our propensity score specification, our results show that the financial support measure had moderately positive effects as it significantly increased the subjective probability to survive the pandemic. We also find important effect heterogeneities as positive effects appear, in particular, for higher educated and more risk tolerant individuals. We further find that the positive effect (a) depends on the speed of the application approval and (b) vanishes as more time passes since the approval.

The rest of the paper is organized as follows. In Section 2, we describe the measures taken to control the pandemic as well as further details on the emergency aid package. Section 3 presents the data used for the empirical analysis and some summary statistics including a description of the economic effects that were observed among the selfemployed,. Section 4 describes the estimation strategy and the propensity score matching approach. Section 5 presents the main estimation results together with the analysis of effect heterogeneities and some robustness checks. Section 6 concludes. 


\section{The COVID-19 Pandemic and Related Policies}

\subsection{The COVID-19 Pandemic in Germany and Related Policy Measures}

At the time of the data collection in April and May 2020, Germany was one of the most affected by the COVID-19 pandemic: over 130,000 people were infected with the Virus SARS-CoV-2. The German government tried to stop the spreading of the virus through several measures with severe impacts on the economy. Schools and daycare centers were closed, as well as most shops, restaurants, and hotels, except for supermarkets. A curfew was imposed, which included a ban on public gatherings of more than two people, except for people living in the same household. People in public areas were required to keep a minimum distance of 1.5 meters. All major and minor events, including trade fairs, sports events, and concerts, were cancelled; travel was restricted. During that time, the Institut für Weltwirtschaft (IfW 2020) predicted a GDP decline of up to $9 \%$ for 2020 . The selfemployed were among the most affected occupational groups, especially those working in the hotel and restaurant business, the tourism industry, the retail sector, the cultural sector, the events sector, and other service industries that require personal contact. For them, the policy measures to contain the epidemic meant, in fact, a temporary prohibition to work, where they could not generate revenues to cover their operating expenses and living costs.

\subsection{Government Support Programs and Emergency Aid Packages}

In order to help the economy and to avoid job cuts as well as a long-lasting recession, the German government introduced several supporting programs to mitigate the consequences of the pandemic. Targeting established firms, employers (including the self-employed employers) could send their employees into Kurzarbeit, short-time work, where the Federal Employment Office covers a substantial portion of the wage costs. This instrument allowed employers to keep their workforce through the crisis while simultaneously protecting employees from losing their jobs and from major wage cuts. However, the self-employed themselves are not covered by this labor market instrument. To address this segment, the government launched an emergency aid package ("Soforthilfe") of $€ 50$ billion, accessible from March 25, 2020 through the end of May 2020. The self-employed were able to apply for this program a couple of days ahead of the official start. The goal of this package was to help solo self-employed and owners of micro firms (with up to 10 employees), who combined account for up about 4.2 million individuals, maintain their ventures and increase their chances of entrepreneurial survival. This group of self-employed individuals could 
receive immediate financial assistance of up to $€ 15,000$ - the maximum amount depended on the number of employees in their businesses, if they were able to demonstrate acute liquidity shortfalls (Federal Ministry for Economic Affairs and Energy, 2020). As a downside of the instrument, the funds from the support program could only be used to cover operating costs; private living costs were excluded.

\subsection{Prior Research on Self-employment During the COVID-19 Pandemic}

The effects of the COVID-19 pandemic on self-employment is attracting empirical research. This research documents that, during the crisis, self-employed workers in other countries suffered in similar ways to those in Germany (Adams-Prassl et al. 2020, Bartik et al. 2020, Graeber et al. 2020). For the U.K., Blundell and Machin (2020) show that three out of four self-employed individuals report a reduced work load. Further, the number of active business owners declined by about $22 \%$ in the US, the largest drop ever recorded (Fairlie 2020). Kalenkoski and Pabilonia (2020), who focus on unincorporated selfemployed workers, reveal that they were about 57 percentage points less likely to be selfemployed in April 2020 relative to February. In Canada, self-employment also fell very strongly: Beland et al. (2020) report an activity decline of $14.8 \%$ for incorporated and $10.1 \%$ for unincorporated entities. These examples show that the decline of selfemployment in response to the pandemic is a global phenomenon. Block et al. (2020) investigate how the self-employed cope with the COVID-19 pandemic and maintain their liquidity, particularly through the use of bootstrap financing. They find that this financing instrument is used by many self-employed, and is, amongst others, positively associated with the severity of the crisis for the venture, the level of private consumption, and selfemployment experience. Finally, using German data, Bertschek and Erdsiek (2020) show that self-employed with a higher degree of digitization are less affected by the crisis.

\section{Data}

\subsection{Data Description of the Estimation Sample}

Our survey took place between April 7 and May 4, 2020. Data was collected via an online survey. The survey, collecting information with respect to the pandemic for the selfemployed, covered the characteristics of the self-employed and their firms. Most importantly, it included questions on whether the self-employed were eligible for government support as well as whether they applied for, and already received it. The survey was administered via the Verband der Gründer und Selbstständigen Deutschland e.V. 
(VGSD) and other professional self-employment associations. ${ }^{4}$ It took place at the beginning of the COVID-19 pandemic while the German economy was locked down.

We collected data from 27,262 respondents. To arrive at the estimation sample matching our research question, we excluded respondents who do not live in Germany and those reporting inconsistent application data, such as application dates before the policy intervention was introduced, or (realized) applications whose application dates were in the future at the time of the survey. Note that we do not exclude respondents who plan to apply for government support, as they serve as control group in our estimation strategy. Second, we also exclude respondents with missing information for any of the variables needed in our propensity score matching. Third, we excluded people for whom we do not have an assessment of their venture surviving the COVID-19 pandemic, as we use this information to create the outcome variable. The final sample comprises 17,090 self-employed individuals.

\subsection{Individual and Venture Characteristics}

In the following, we briefly describe our sample, starting with the individual and venture characteristics. Table 14 in the appendix shows descriptive statistics for the whole sample and the subsamples used in the propensity score matching analysis. Starting with the age of the self-employed, 22\% of the respondents are younger than 39 years, $28 \%$ are between 40 and 49 years, $37 \%$ are between 50 and 59 years, and $13 \%$ are older than 60 years. Men comprise $49 \%$ of the respondents. The average education level is high with $61 \%$ of the respondents having a university degree. Most respondents are located in North RhineWestphalia (21\%), followed by Bavaria (17\%), Berlin (11\%), and Baden-Württemberg $(10 \%)$.

Respondents could also indicate their willingness to take risks on a 5-point scale ranging from 1 (complete unwillingness) to 5 (complete willingness). We group the answers into three categories - low risk tolerance (1/2), medium risk tolerance (3), and high risk tolerance (4/5) -, finding that the reported risk tolerance levels are approximately uniformly distributed among self-employed. About $90 \%$ of the respondents work full-time and $62 \%$ of the respondent report monthly living expenditures of $€ 1,000$ to $€ 2,500$. With regard to industry distribution, $41 \%$ of the respondents are from the cultural, entertainment, and recreation sector, followed by information and communication (12\%), education $(12 \%)$, and health (8\%). The share of solo self-employment is relatively high: $79 \%$ of the

\footnotetext{
${ }^{4}$ The VGSD is one of the largest associations of self-employed in Germany.
} 
respondents have no employees. The mean value of digitization on a scale from 1 to 5 is 2.89. Last, but not least, the respondents report that they are, on average, experienced with respect to self-employment: $81 \%$ of the respondents have more than five years of selfemployment experience, with $56 \%$ having more than ten years.

\subsection{Financial Loss due to the COVID-19 Pandemic}

Figure 1 to Figure 3 summarize the financial situation of the self-employed during the COVID-19 pandemic, as reported in the survey, distinguishing between respondents who applied for the emergency aid and those who did not. ${ }^{5}$ Figure 1 reveals that the revenue decline due to the COVID-19 pandemic was more pronounced among those who applied for the support program than those who did not. About $43 \%$ of the applicants lost all of their income against $31 \%$ of the non-applicants. Similarly, applicants experienced higher monthly financial losses on average (Figure 2).

Figure 1: Revenue decline due to the COVID-19 pandemic

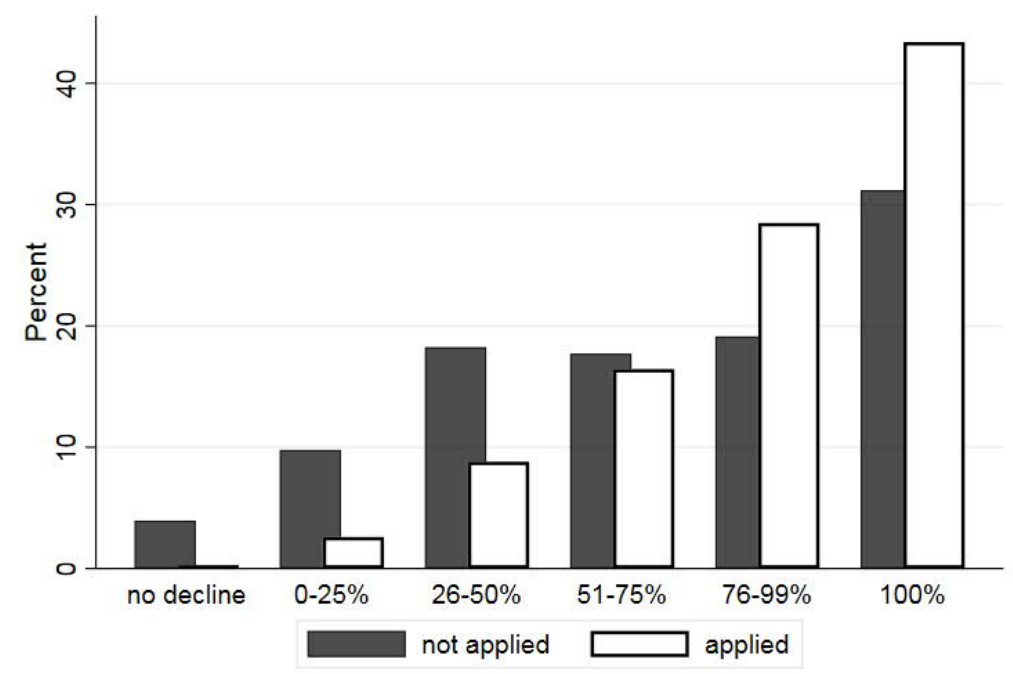

5 These figures give a general overview over the self-employed during the pandemic and shall not be mixed-up with information on the treatment and control group in our propensity score analysis. We will properly define the treatment and control group in Section 4.2) 
Figure 2: Monthly financial loss during the crisis

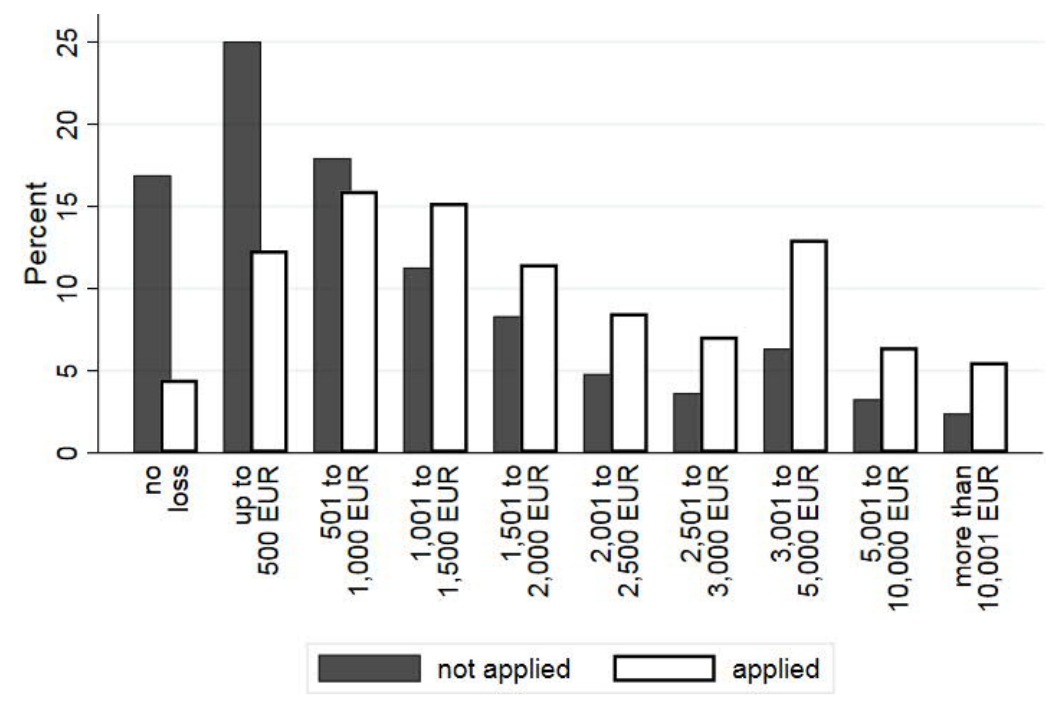

Table 1 reports that a large share of respondents faced substantial declines in their revenues due to the pandemic; still economic sectors were affected in very different ways. The hotels and restaurants industry, as well as the arts, recreation and cultural activities were hit particularly hard by the economic lockdown. In these industries, the majority of the applicants report that they have no more revenues at all, with 9 out of 10 having to compensate for declining revenues of more than $75 \%$.

Table 1: Revenue decline by industry

\begin{tabular}{|c|c|c|c|c|}
\hline \multicolumn{5}{|c|}{$\begin{array}{l}\text { Share of respondents within each industry with a revenue decline due to the } \\
\text { COVID-19 pandemic of... }\end{array}$} \\
\hline \multirow[b]{2}{*}{ industry } & \multicolumn{2}{|c|}{ applicants } & \multicolumn{2}{|c|}{ non-applicants } \\
\hline & $\begin{array}{l}76 \text { to } \\
99 \%\end{array}$ & $\begin{array}{c}100 \% \\
\text { (no more } \\
\text { revenue) }\end{array}$ & $\begin{array}{l}76 \text { to } \\
99 \%\end{array}$ & $\begin{array}{c}100 \% \\
\text { (no more } \\
\text { revenue) }\end{array}$ \\
\hline manufacturing & 0.29 & 0.20 & 0.19 & 0.10 \\
\hline trade, repairing of motor vehicles & 0.33 & 0.29 & 0.19 & 0.20 \\
\hline hotels and restaurants & 0.27 & 0.64 & 0.13 & 0.68 \\
\hline information and communications & 0.35 & 0.19 & 0.23 & 0.12 \\
\hline professional services & 0.28 & 0.32 & 0.17 & 0.27 \\
\hline other services & 0.23 & 0.31 & 0.10 & 0.27 \\
\hline education & 0.31 & 0.45 & 0.22 & 0.41 \\
\hline health care and social services & 0.30 & 0.23 & 0.16 & 0.27 \\
\hline arts, recreation, cultural activities & 0.27 & 0.56 & 0.20 & 0.44 \\
\hline $\begin{array}{l}\text { other } \\
\text { oth }\end{array}$ & 0.26 & 0.42 & 0.17 & 0.32 \\
\hline
\end{tabular}

When asked about the number of months, they could remain solvent without government aid under the given income situation, non-applicants report an average of 4 months. The majority of applicants, on the other hand, declare that they would not survive more than 2 months without support from the government (Figure 3, left panel). The 
additional use of private reserves extends the solvency by around one month (Figure 3, right panel). In summary, the descriptive evidence shows how severely the crisis affected the applicants and that the emergency program seems to have partially succeeded in terms of targeting those who needed financial support.

\section{Figure 3: Duration of solvency without government support}
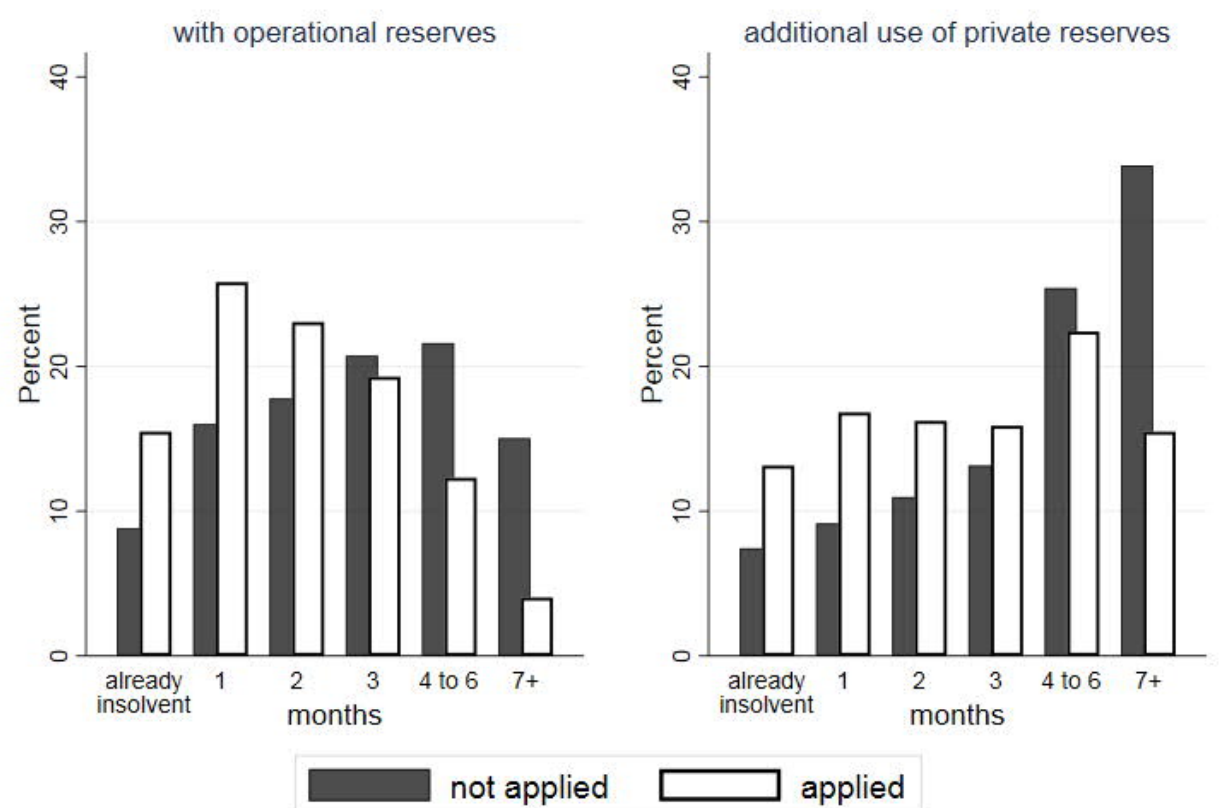

\subsection{Future Prospects}

With respect to their future prospects, applicants and non-applicants appear to form similar expectations. In spring 2020, the majority of the self-employed expected financial hardship to continue for about half a year (Figure 4) and was weakly optimistic about their venture surviving the pandemic over the next 12 months (Figure 5). Still, we find minor differences between applicants and non-applicants with applicants being slightly more pessimistic about the future.

Figure 4: Expected duration of financial hardship due to the COVID-19 pandemic

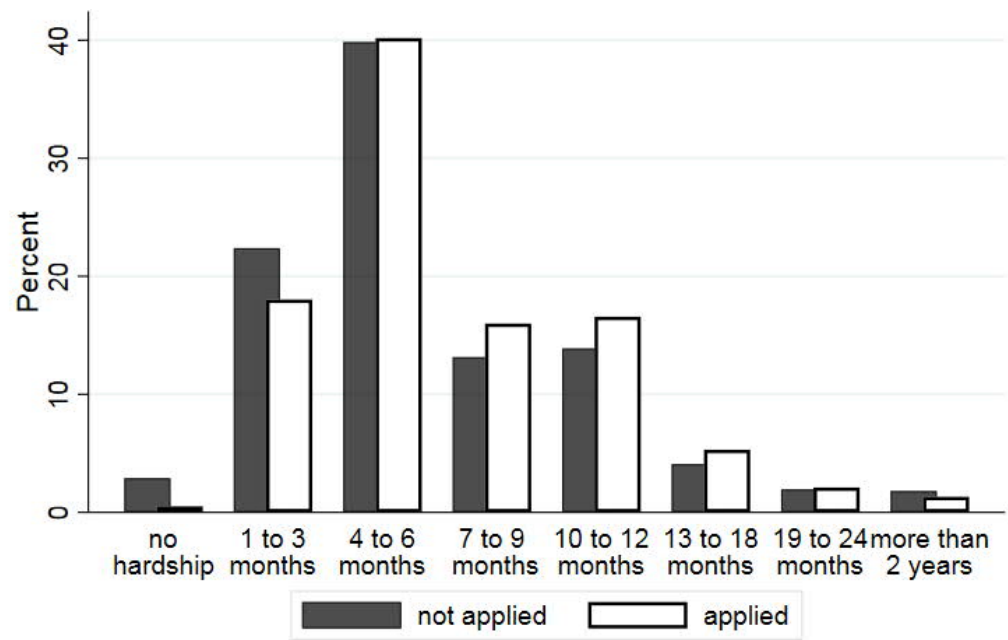


Figure 5: Expected probability of occupational survival during the next 12 months

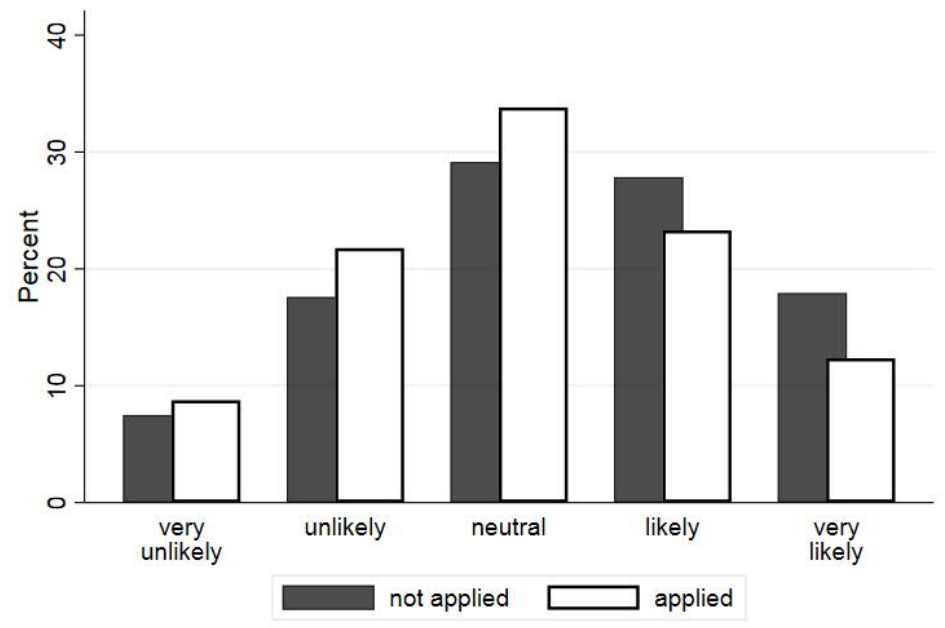

\subsection{Emergency Aid Program}

Figure 6 shows the survey within the timeframe of the emergency aid program. The survey began 3 weeks after the start of the emergency program and was online for three and a half weeks until May 4, 2020. On April 22, 2020, the professional service associations reminded their members to participate in the survey. Applications for the first round of the emergency program could be made through the end of May, when it was replaced with a different support program that was designed for micro and small-sized firms, less for (solo-)selfemployed, and which could only be applied for through a tax advisory firm ("Übergangshilfe I"). ${ }^{6}$

Figure 6: Distribution of survey responses over time

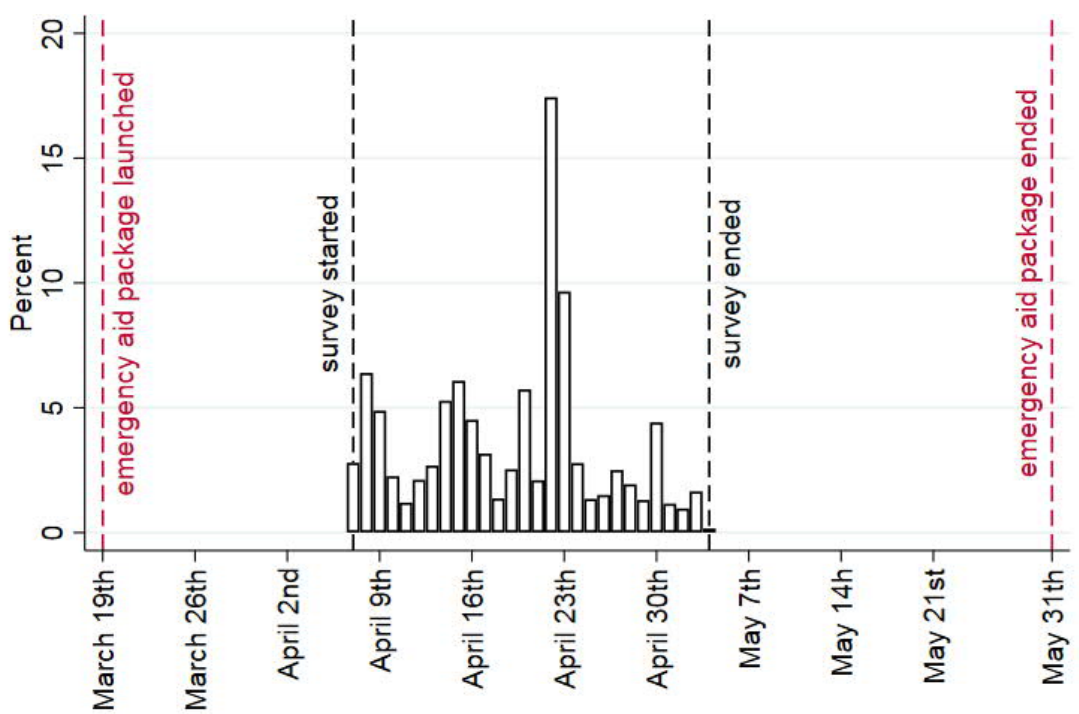

6 See the press release by the Federal Ministry for Economic Affairs and Energy of July 8, 2020, for details. (https://www.bmwi.de/Redaktion/EN/Pressemitteilungen/2020/20200708-launch-of-the-federalgovernment-coronavirus-bridging-aid-instrument.html, accessed December 14, 2020). 
Table 2 provides an overview of the respondents' application status in our sample, as well as a description of the non-applicants regarding their plans to apply later on. We observe 10,001 applicants in our sample, of which two-thirds successfully applied for the emergency aid program and 58\% had received the lump sum payment at the time of the survey. The processing took an average of 7.5 days with half of the applicants receiving their payment within 5 days. At the time of being surveyed, one-third of the applicants were still awaiting a decision. Note that rejection rates were very low (244 of 10.001).

Table 2: Number of applicants vs. non-applicants

\begin{tabular}{|c|c|c|}
\hline & $\mathbf{N}$ & $\begin{array}{l}\% \text { of whole } \\
\text { sample }\end{array}$ \\
\hline Number of applicants & 10,001 & $59 \%$ \\
\hline ... with application approved & 6,440 & $38 \%$ \\
\hline ... with payment received & 5,814 & $34 \%$ \\
\hline $\begin{array}{l}\text { av. duration in days from } \\
\text { application to payout (median/mean) }\end{array}$ & $5 / 7.5$ & \\
\hline ...waiting for decision & 3,317 & $19 \%$ \\
\hline av. number of days waiting (median/mean) & $15 / 15.9$ & \\
\hline ...with application rejected & 244 & $1 \%$ \\
\hline Number of non-applicants & 7,089 & $41 \%$ \\
\hline ... planning to apply & 1,027 & $6 \%$ \\
\hline$\ldots$ unsure whether to apply or not & 2,981 & $17 \%$ \\
\hline ... decided not to apply & 3,081 & $18 \%$ \\
\hline
\end{tabular}

Figure 7: Timing of the application process

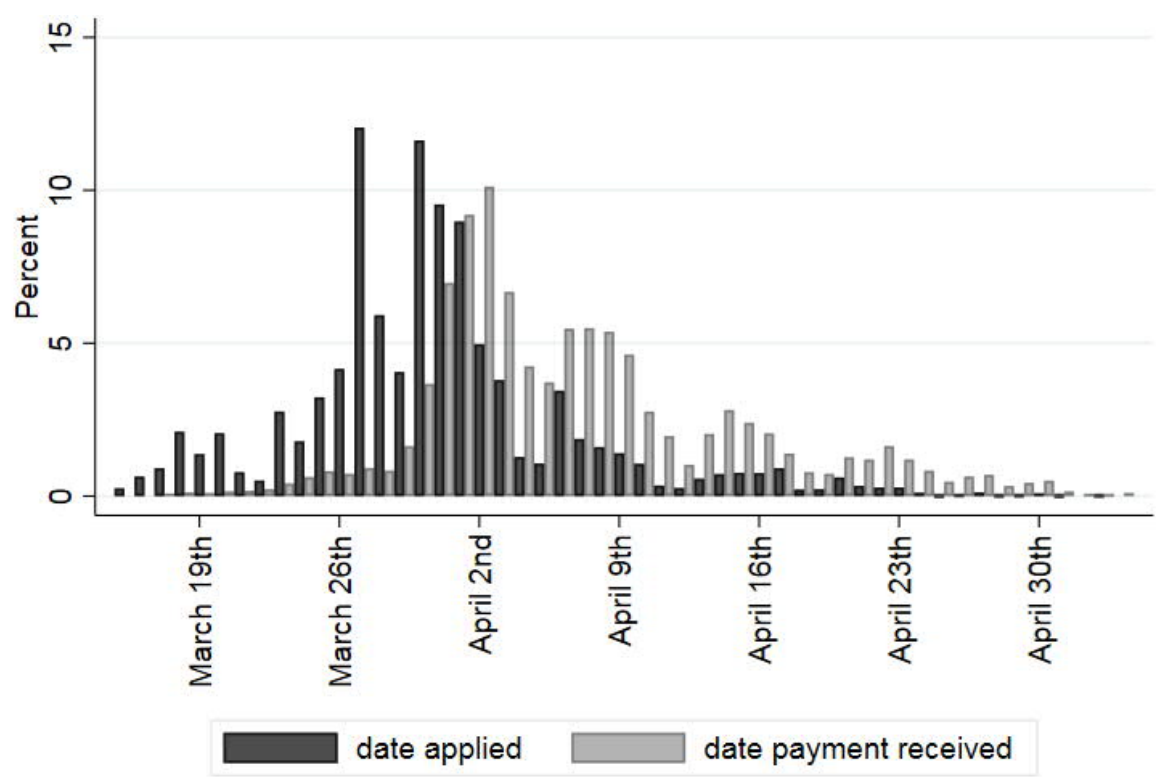

Figure 7 illustrates the distribution of applications and payouts over time, showing that most applications were made within the first three weeks after the program was launched. The federal program officially started on March 25, 2020. Some of the 16 German federal states started similar programs earlier than the federal government: the earliest was Bavaria on March 19, 2020. From April 1, 2020 all state and federal level programs were merged to one single program, while in the initial period during March 2020 applicants had to decide whether they applied for a state or a federal program. 


\section{Estimation Strategy}

\subsection{The Identification of Causal Treatments Effects}

We investigate to what extent the emergency aid program increased the probability of the self-employed to get through the crisis with the same venture during the COVID-19 pandemic. In order to estimate causal effects, we rely on the Roy (1951) - Rubin (1974) model with two potential outcomes, $Y_{1}$ and $Y_{0}$, and a binary treatment variable $D_{i}$ equal to one if the individual receives the treatment and equal to zero otherwise. Since the counterfactual outcome is not observable, i.e., we do not observe the outcome of the treated if they were not treated and vice versa, we cannot estimate the individual treatment effect. Instead, we rely on population averages and consider the average treatment effect of the treated defined as

$$
\mathrm{ATT}=\mathrm{E}\left[\mathrm{Y}_{1} \mid \mathrm{D}=1\right]-\mathrm{E}\left[\mathrm{Y}_{0} \mid \mathrm{D}=1\right]
$$

and the average treatment effect of the sample population. This is composed of the average treatment effect of the treated (ATT) and the average treatment effect of the untreated (ATU) weighted by their respective proportions in the sample $\pi$ and (1- $\pi$ ):

$$
\begin{aligned}
\mathrm{ATE} & =\mathrm{E}\left[\mathrm{Y}_{1}\right]-\mathrm{E}\left[\mathrm{Y}_{0}\right]=\mathrm{ATT}+\mathrm{ATU} \\
& =\pi\left(\mathrm{E}\left[\mathrm{Y}_{1} \mid \mathrm{D}=1\right]-\mathrm{E}\left[\mathrm{Y}_{0} \mid \mathrm{D}=1\right]\right)+(1-\pi)\left(\mathrm{E}\left[\mathrm{Y}_{1} \mid \mathrm{D}=0\right]-\mathrm{E}\left[\mathrm{Y}_{0} \mid \mathrm{D}=0\right]\right)
\end{aligned}
$$

Approximating the unobservable average outcome of the treated under no treatment $E\left[Y_{0} \mid D=1\right]$ by the observable average outcome of the control group, $E\left[Y_{0} \mid D=0\right]$, leads to a selection bias since $\mathrm{E}\left[\mathrm{Y}_{0} \mid \mathrm{D}=1\right]$ usually does not equal $\mathrm{E}\left[\mathrm{Y}_{0} \mid \mathrm{D}=0\right]$ in nonexperimental data, as individuals self-select into treatment and most likely differ from the control group along several dimensions. The same applies for $\mathrm{E}\left[\mathrm{Y}_{1} \mid \mathrm{D}=0\right]$. We overcome this by assuming conditional independence, i.e., conditional on observable characteristics $\mathrm{X}$, the potential outcome is independent of treatment assignment, obtaining

$$
\mathrm{ATT}=\mathrm{E}\left[\mathrm{Y}_{1} \mid \mathrm{X}, \mathrm{D}=1\right]-\mathrm{E}_{\mathrm{X}}\left[\mathrm{E}\left[\mathrm{Y}_{0} \mid \mathrm{X}, \mathrm{D}=0\right] \mid \mathrm{D}=1\right]
$$

and

$$
\begin{aligned}
\mathrm{ATE}= & =\mathrm{E}\left[\mathrm{Y}_{1} \mid \mathrm{X}, \mathrm{D}=1\right]-\mathrm{E}_{\mathrm{X}}\left[\mathrm{E}\left[\mathrm{Y}_{0} \mid \mathrm{X}, \mathrm{D}=0\right] \mid \mathrm{D}=1\right] \\
& +\mathrm{E}_{\mathrm{X}}\left[\mathrm{E}\left[\mathrm{Y}_{1} \mid \mathrm{X}, \mathrm{D}=1\right] \mid \mathrm{D}=0\right]-\mathrm{E}_{0}\left[\mathrm{Y}_{0} \mid \mathrm{X}, \mathrm{D}=0\right]
\end{aligned}
$$

The outer expectation $E_{X}[. \mid D=$.$] conveys that the individuals from the comparison$ group are matched to the treated units in such way that the mean distribution of the 
covariates in the matched control group resembles that of the treatment group for the calculation of the ATT and vice versa for the ATU (Caliendo and Kopeining, 2008). Furthermore, we assume overlap with $0<\operatorname{Pr}(\mathrm{D}=1 \mid \mathrm{X})<1$ for all $\mathrm{X}$, meaning that individuals with the same values for $\mathrm{X}$ have a positive probability of being treated and untreated, i.e., there is no determinism in treatment assignment based on the covariates. We apply propensity score matching to reduce the dimensionality of the covariates to a single balancing score, $\mathrm{P}(\mathrm{X})$, based on which individuals from the control group are matched to the treatment group for the ATT and vice versa for the ATU.

\subsection{Estimation procedure}

\section{Outcome variable}

The aim of the emergency aid program was to help the self-employed to financially survive the crisis. In the survey, the respondents are asked to assess the likelihood of quitting selfemployment within the next 12 months due to the COVID-19 pandemic. We use this information to construct our outcome variable, capturing the subjective survival probability of the respondents' ventures ranging from 1 ("very unlikely") to 5 (very likely"). Section 3.4, Figure 5, shows the distribution of the variable in our sample, distinguishing between applicants and non-applicants. For our causal analysis, we reduce this ordinal variable to a binary variable where the categories 5 ("very likely") and 4 ("rather likely") equal one, and the remaining categories 3 ("neutral"), 2 ("rather unlikely”), and 1 (“very unlikely") equal zero. As a robustness check we use the ordinal variable as dependent variable. The results are qualitatively very similar (see Section 5.3).

\section{Treatment variable}

We asked respondents to indicate whether they had applied or planned to apply for the emergency aid program. Possible answers are 1 (“yes, I applied”), 2 (“I am planning to apply"), 3 ("I am not sure yet"), and 4 ("I will not apply"). We combine this question with information on their application's status ranging from 1 ("approved"), over 2 ("was rejected") to 3 ("I am waiting for a decision"). We also have information on the payment status for those individuals with approved application. As a result, we obtain a detailed variable on the respondents' application status for the emergency aid program, which we illustrate in Table 3: Possible values are 1 ("I applied and the aid was already paid out to me"), 2 ("I applied and the aid was approved, but not yet paid out to me"), 3 ("I applied, 
but my application was rejected"), 4 ("I applied and I am waiting for a decision"), 5 ("I am planning to apply"), 6 ("I am not sure yet"), and 7 ("I will not apply")

Table 3: Definition of the treatment and control group

\begin{tabular}{|c|c|c|c|c|}
\hline \multicolumn{5}{|c|}{ Treatment vs. control group } \\
\hline \multirow[t]{2}{*}{ I applied } & My application wa & ... approved & $\begin{array}{l}\text {... rejected } \\
\text { (3) }\end{array}$ & $\begin{array}{l}\text {... waiting for decision } \\
\text { (4) }\end{array}$ \\
\hline & $\begin{array}{l}\text { The aid was... paid out } \\
\text { (1) }\end{array}$ & $\begin{array}{c}\text {...not yet paid out } \\
\text { (2) }\end{array}$ & & \\
\hline \multicolumn{5}{|c|}{$\begin{array}{l}\text { I am planning to apply } \\
(5)\end{array}$} \\
\hline \multicolumn{5}{|c|}{$\begin{array}{c}\text { I am not sure yet } \\
(6)\end{array}$} \\
\hline \multicolumn{5}{|c|}{$\begin{array}{l}\text { I will not apply } \\
(7)\end{array}$} \\
\hline
\end{tabular}

treatment group

control group

We are interested in the occupational survival probability of those individuals that actually obtained the emergency aid and, therefore, define all respondents in category 1 as our treatment group ( $\mathrm{n}=5,803)$. Furthermore, we follow Sianesi (2004) and Fredriksson and Johansson (2008) in using respondents who are planning to apply as a control group $(\mathrm{n}=1,027)$. The advantage is that respondents who are inclined to apply might share important characteristics with those that have already applied regarding their financial situation, their venture's characteristics etc. compared to individuals that did not apply. However, respondents who are planning to apply might still differ from the treatment group in that their need for support is less urgent (which is why they have not yet applied). A straightforward explanation could be that they were either (a) financially less affected by the crisis, or (b) have alternative sources of finance, e.g., own financial reserves or support through alternative government programs. We address these issues in the propensity score matching algorithm by controlling for the revenue decline, for the estimated time to insolvency after taking into account financial reserves, and for transfers from the basic income scheme, among other variables influencing selection into treatment (see the following paragraph 'Propensity score matching'). ${ }^{7}$ While these factors should be the main

7 Evaluating information on further government support programs, we observe that $21 \%$ of the control group have applied for alternative government support programs against $16 \%$ of the treatment group. Therefore, in the vast majority of the cases, financial support from alternative government programs than the emergency aid program and the basic income scheme does not explain the control group's decision to postpone the application. As a robustness check, we estimated an alternative model controlling for further government support programs in the propensity score matching. The results are largely the same and available upon request from the authors. 
reasons for postponing the application, we cannot rule out that other, unobservable factors motivate their decision. In this case, we would most likely underestimate the treatment effect from the emergency program, i.e. if the control group's decision to postpone their application is associated with a higher survival probability than the counterfactual survival probability of the treatment group.

Note that we exclude respondents whose application was successful but to whom the aid was not yet paid out at the time of the survey (category 2), as those individuals are difficult to classify between the treatment and control groups. Knowing the exact amount of financial support they will receive, they are probably very close to the treatment group if their expectations about their ventures' survival probability anticipate the lump sum payment. However, having not yet received the financial support, they might be more conservative in their expectations, because the exact date of the payout is still uncertain and they have to bridge the time financially. If the latter effect dominates, including them in the treatment group would negatively bias the average outcome of the treatment group. Furthermore, we decided against using individuals waiting for a decision (category 4) as a control group, since the average time that has elapsed since their application (15 days, see Section 3.5, Table 2) well exceeds the average processing time ( 7.5 days), suggesting that their applications somehow differ from the average (e.g., their cases are more complicated) and it is unclear how the uncertainty about the (date of) approval affects their expectations about their future prospects.

As we are interested in the treatment effect for all self-employed targeted by the emergency fund, we estimate both the ATT and ATE, since it is reasonable to believe that the majority of the self-employed who planned to apply are also eligible for the emergency aid (Table 2 shows a rejection rate of $2.4 \%, 244$ of 10,001). It can be assumed that a large fraction of them will join the program at a later point in time (Sianesi, 2004).

\section{Propensity score matching}

We apply propensity score matching to match treated and untreated individuals based on a set of covariates that are likely to affect the application for the emergency aid as well as the respondents' expectations about their ventures' prospects. Notably, we estimate the probability of having successfully applied for the aid scheme and obtained financial support from the emergency fund versus being still in the state of planning to apply for funding in a probit model using the following covariates. We start with relevant personal characteristics, including the respondent's age measured as an ordinal variable scaled from 
1 (<30 years) to 5 (> 59 years) and a binary variable capturing gender, accounting for gender-related differences in their venture and investment strategies when they are selfemployed (Kautonen et al. 2014, Bendell et al. 2019). Similarly, we control for the respondents' self-employment experience by accounting for the number of years that the individual spent as self-employed. To control for the respondent's level of education, we include a binary variable equal to one if the respondent received an academic education and zero otherwise. Empirical studies show that the level of education influences entrepreneurial performance and survival (Kato and Honyo 2015, Parker et al. 2006, Van der Sluis et al. 2008). Reasons include differences in cognitive abilities and the skill to identify and exploit entrepreneurial opportunities (Hartog et al. 2010), differences in opportunity costs (Gimeno et al. 1997), and better adaptability of higher educated individuals to changing environments (Stasielowicz 2020). Furthermore, we measure the self-employed respondents' attitudes toward risk on a scale from 1 (low risk tolerance) to 5 (high risk tolerance) (Dohmen et al., 2011). ${ }^{8}$ Prior research shows that risk tolerance affects entrepreneurial survival (Caliendo et al. 2010).

In addition to the individual characteristics, we control for a range of venture-related factors that are likely to influence selection into treatment and the outcome variable. First, we include information as to whether the self-employed work full-time or part-time in their ventures and whether they have employees or not; since prior research documents different survival probabilities for these groups in comparison to other self-employed persons (de Vries et al. 2019, Raffiee and Feng 2014). Moreover, we expect both the full-time selfemployed and the solo self-employed to be more vulnerable to revenue decreases during the COVID-19 pandemic and, therefore, more likely to apply for emergency aid. Secondly, we take into account the degree of digitization of the firm before the pandemic started, as we expect that ventures with a higher degree of digitization can more easily adapt their service provision to the requirements of the containment measures, e.g., regarding customer relations (Bertschek and Erdsiek 2020). To obtain this information, we ask respondents to indicate their ventures' level of digitization before the pandemic started on a 5-point Likert scale. Based on this scale, we construct a binary variable that is equal to one for respondents who stated that their ventures possessed either a high or a very high degree of digitalization. As the impact of the COVID-19 crisis differs across industries, we

8 Previous research emphasizes that even individuals with high risk tolerance are at the maximum risk neutral - there is no significant share in the population that is risk seeking (see e.g. Caliendo et al. 2010, Dohmen et al. 2011). 
account for imbalances in the industry structure between the treatment and control groups by including a set of industry fixed effects that indicate the main industry of the respondent's venture. The industrial categorization differentiates ventures engaged in (a) IT, (b) engineering, (c) business services, (d) training, (e) proof-reading, (f) journalism, (g) culture, (h) event, (i) health and wellness, (j) tourism, (k) retail, (l) online retail, (m) finance and real estate, (n) hospitality, and (o) others. Finally, the measures taken by the government in reaction to the COVID-19 crisis also differed across the 16 German federal states. To capture these differences as well as the more general regional differences across Germany in the socio-economic structure and it its impact on self-employment (Fritsch et al. 2006), we include region fixed effects for the federal state in which the respondents' venture is located.

Lastly, we control for the respondents' financial situations. Prior research shows that wealth, living costs and household income are important determinants of entrepreneurial behavior and success (Holtz-Eakin 1994, Hurst and Lusardi 2004, Parker and Van Praag 2006). We construct the following measures: First, we use information on the respondents' monthly private cost of living. Possible values range from 1 (0-500€) to 11 (more than $5,000 €)$. Second, we measure whether they received financial support from the basic income scheme. Third, we use information on how their ventures were affected by the crisis. We capture the ventures' solvency via a range of dummy variables. Specifically, we asked respondents to indicate how long their ventures would be able to maintain solvency given their current revenue and cost situations. The categories are (a) already insolvent, (b) solvent for one month, (c) solvent for two months, (d) solvent for three months (e) solvent for 4 to 6 months, and (f) solvent for more than 6 months. Furthermore, we account for reported revenue decreases as a consequence of the COVID-19 pandemic with possible values ranging from (a) $100 \%$, over (b) 76 to $99 \%$, (c) 51 to $75 \%$, (d) 26 to $50 \%$, (e) 1 to $25 \%$, to (f) no decline. Table 14 in the Appendix summarizes the covariates used and compares their realized value distribution between the unmatched sample and the treatment and control groups within the matched sample.

To ensure overlap, we trim the matching sample to observations within the region of common support using the $\max (\min \{\mathrm{P}(\mathrm{X}) \mid \mathrm{D}=1, \mathrm{P}(\mathrm{X} \mid \mathrm{D}=0)\}$ and $\min (\max \{\mathrm{P}(\mathrm{X}) \mid \mathrm{D}=1$, $\mathrm{P}(\mathrm{X} \mid \mathrm{D}=0)\}$ condition at the tails of propensity score distribution. We use an Epanechnikov kernel to construct a weighted average of the control units for the calculation of the counterfactual outcome, with the kernel bandwidth being chosen by cross-validation. The advantage of the kernel matching estimator over other techniques is that we use information 
from a range of control units instead of relying on a small set of matching partners in the close neighborhood of the treated unit. This is particularly relevant in our case as the control group is smaller than the treatment group, which would require high replacement rates for neighborhood matching potentially leading to inefficient ATT estimates (Caliendo and Kopeining 2008). As a robustness check, we re-estimate our main results with different matching estimators in Section 5.3. We bootstrap standard errors for the average treatment effects based on $\mathrm{B}=1,999$ replications.

\subsection{Matching Quality}

We operationalize the categorical variables $X$ by a set of dummy variables resulting in a total amount of 63 variables in the propensity score matching. Before matching, roughly half of the variables show significant differences in means at the 5\% level using a t-test, which reduces to 14 variables after matching (Table 4, row 6). In addition, we calculate the standardized bias according to Rosenbaum and Rubin (1985), finding that the number of variables with absolute standardized biases above 5\% and the mean absolute standardized bias are substantially reduced after matching (Table 4, rows 1-5 and 8), with a mean value below $5 \%$ being generally considered a successful bias reduction (Caliendo and Kopeining, 2008). Alternatively, one can rely on two measures developed by Rubin (2001) to separately analyze the matching effect on bias reduction and variance. To analyze bias reduction, Rubin suggests comparing the number of standard deviations between the means of the covariate distributions for the treatment and control groups -- usually referred to as Rubin's B - arguing that standard deviations should be less than half a standard deviation apart after matching, preferably even less than one quarter. We obtain a value of 0.24 , showing that we successfully reduced the bias between treatment and control groups (Table 4, row 9). Since there is a well-known trade-off between bias reduction and variance (Caliendo and Kopeining 2008), we also analyze Rubin's R, i.e., the ratio between the propensity score's variances in both groups before and after the matching. Ideally, the ratio should be close to one and not exceed [0.5; 2] (Rubin 2001). Table 4, row 10 illustrates that the bias reduction is indeed accompanied by an increase in variance from 0.98 to 1.13 ; however, the obtained ratio in variances is still close to 1 . Finally, re-estimating the propensity score after matching obtains a Pseudo- $\mathrm{R}^{2}$ of 0.01 , meaning that the remaining variation in the treatment participation after matching cannot be explained with the covariates, i.e., there are practically no systematic differences in the distribution of covariates between the treated and controls after matching (Table 4, row 11). To sum up, 
the various measures indicate that the matched sample is balanced and conditional on the covariates, potential outcomes are independent of treatment.

Table 4: Matching quality

\begin{tabular}{|l|c|c|}
\hline & Before matching & After matching \\
\hline Number of variables & & \\
....with absolute standardized bias of & 3 & 13 \\
0 to less than 1\% & 13 & 32 \\
1 to less than 3\% & 10 & 12 \\
3 to less than 5\% & 16 & 5 \\
5 to less than 10\% & 21 & 1 \\
more than 10\% & 32 & 14 \\
...with significant differences in means (at 5\% level) & 63 & 63 \\
\hline ... in total & 6.4 & 1.8 \\
Mean absolute standardized bias in \% & 0.94 & 0.24 \\
Rubin's B & 0.98 & 1.13 \\
Rubin's R & 0.13 & 0.01 \\
\hline (Re-)estimation of the propensity score: Pseudo- $\mathbf{R}^{\mathbf{2}}$ & & \\
\hline
\end{tabular}

In addition to conditional independence, we require that the propensity score distributions of the treated and untreated overlap; i.e. there are no propensity score $\mathrm{P}(\mathrm{X})$ perfectly predicting treatment or non-treatment. Figure 8 shows the propensity score distribution for both groups. As expected, the distribution of the treatment group is left-skewed with treated individuals having a higher probability of being treated than the untreated. However, we find sufficient common support for the approximate interval of [0.20;0.99] and importantly -- there are no holes, i.e., we do not observe areas out of common support within the interval [0.20;0.99], which otherwise would invalidate our trimming approach based on the min-max-criterion.

Figure 8: Common support

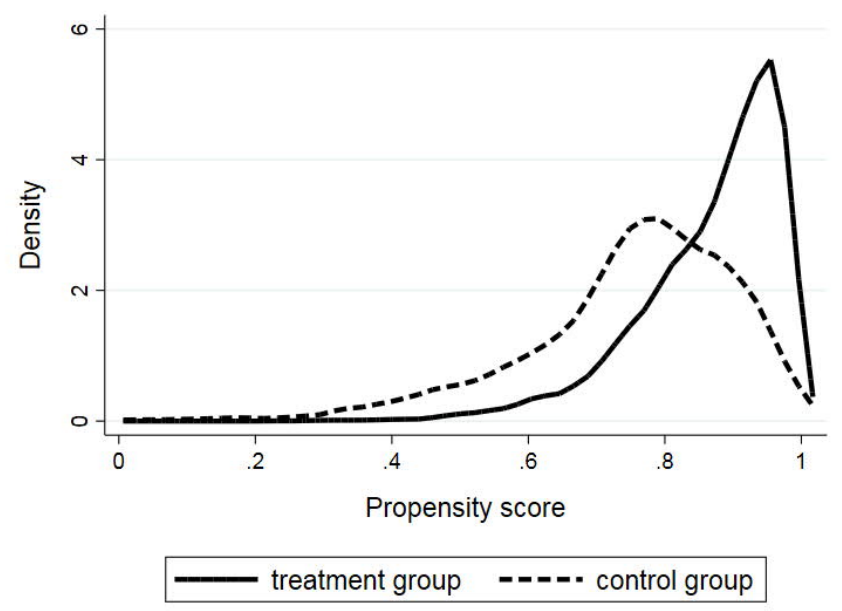




\section{Econometric Results}

\subsection{Main Results}

Table 5 shows the estimated average treatment effects for the whole treatment group, both for a trimmed model applying the min-max-criterion and for a more conservative trimming model with an upper bound of 0.95 . On average, the emergency aid moderately increases subjective survival probability among self-employed who received the financial support by 4.4 percentage points, the effect is marginally significant at $6 \%$ (Table 5, column 1). Comparing this effect to support measures that sought to increase the survival of start-ups (see, inter alia, Caliendo and Künn 2011, Caliendo et al. 2016), they find effects of about the double effect size. In this context it needs to be taken into account that the emergency aid consisted only of a one-time lump sum payment, while the start-up subsidies comprised repeated payments for several months. Therefore, it is worth noting that the one-time lump sum payment does affect the subjective survival probability at all, despite its limited time horizon. Still, the weak level of significance might indicate that the average effect across the whole treatment population is limited. We address this in Section 5.2, shedding more light on heterogeneous effects between subgroups.

One might be concerned that the upper bound is still very close to unity and, therefore, includes respondents with a nearly perfect prediction of being treated. Excluding persons from the treatment group that have a propensity score close to 1 does not substantially alter the results (Table 5, column 2). However, note that the conservative model discards a large number of treated units, questioning whether the estimated effect is still representative of the treated individuals. Therefore, we focus on the min-max-criterion in the subsequent analyses.

Table 5: ATT for the main sample

\begin{tabular}{|l|r|r|}
\hline & \multicolumn{2}{|c|}{ Trimming approach } \\
min/max & min /.95 \\
\hline ATT & 0.044 & 0.040 \\
\hline SE & $(0.023)$ & $(0.022)$ \\
p-value & 0.058 & 0.073 \\
common support & {$[0.241,0.997]$} & {$[0.241,0.950]$} \\
N matched & 6766 & 5419 \\
N unmatched & 43 & 1 \\
N out of common support & 21 & 1410 \\
\hline N total & 6830 & 6830 \\
\hline
\end{tabular}

If we include the hypothetical effect on the control group, i.e., changes in the subjective survival probability of the respondents who are planning to apply for the emergency fund (if they did and received the payment), we obtain an average treatment effect of the whole sample population of $4.5 \%$, which is nearly identical to the ATT. 
Table 6: ATE for the main sample

\begin{tabular}{|l|r|r|}
\hline & \multicolumn{2}{|c|}{ Trimming approach } \\
\hline ATE & 0.045 & $\min / .95$ \\
\hline SE & $(0.021)$ & 0.042 \\
p-value & 0.031 & $(0.021)$ \\
common support & 0.042 \\
N matched & $0.241,0.997]$ & {$[0.241,0.950]$} \\
N unmatched & 6766 & 5419 \\
N out of common support & 43 & 1 \\
\hline N total & 21 & 1410 \\
\hline \multicolumn{2}{|c|}{ Notes: Standard errors were bootstrapped with $B=1,999$ replications. } \\
\hline
\end{tabular}

\subsection{Timing Effects and Effect Heterogeneities}

The ATT in the main sample measures the average program effect across all individuals who received financial support from the emergency fund. We are further interested in knowing whether some individuals benefitted more than others based on their exposure to the crisis, their personal characteristics, or the application process. In the following section, we explore potential differences in the effect size across important subgroups.

\subsubsection{Individual and venture characteristics}

Risk

Since the self-employed person's willingness to take risks affects corporate strategy and corporate results -- including survival probability (Caliendo et al. 2010, 2014) -- we start by distinguishing between subgroups reporting different levels of risk tolerance. Table 7 lists the results. We find that the support from the emergency fund seems particularly helpful for persons with high risk tolerance (category 3). Their subjective survival probability as self-employed increased by 11.5 percentage points compared to those who have not yet applied for the program. Interestingly, we do not find a significant effect among the more risk averse self-employed: the support from the emergency fund did not measurably increase their subjective survival probability. A potential explanation could relate to differences in the investment strategy between self-employed with different risk tolerance. The more risk tolerant self-employed who are generally more willing to make risky investments (Caliendo et al. 2010), and may have higher confidence in their own skills, might accordingly have invested the lump sum payment into adjustment measures to deal with the pandemic, e.g., into digitization. The less risk tolerant individuals - being generally less willing to make risky investments - might save the lump sum payment at a bank account, instead of covering expected losses or investing them into their venture. 
Consequently, the lump sum payment does not have a lasting effect on their perception regarding the survival of their venture over the next 12 months.

Table 7: ATT by risk tolerance

\begin{tabular}{|c|c|c|c|}
\hline \multicolumn{4}{|c|}{ Risk attitude } \\
\hline & $\begin{array}{l}\text { Low risk } \\
\text { tolerance }\end{array}$ & $\begin{array}{c}\text { Medium risk } \\
\text { tolerance }\end{array}$ & $\begin{array}{l}\text { High risk } \\
\text { tolerance }\end{array}$ \\
\hline $\begin{array}{l}\text { ATT } \\
\text { SE } \\
\text { p-value } \\
\text { common support } \\
\text { N matched } \\
N \text { unmatched } \\
N \text { out of common support }\end{array}$ & $\begin{array}{r}\mathbf{0 . 0 2 8} \\
(0.045) \\
0.532 \\
{[0.237,0.972]} \\
1707 \\
24 \\
125 \\
\end{array}$ & $\begin{array}{r}-0.006 \\
(0.042) \\
0.879 \\
{[0.192,0.997]} \\
2236 \\
192 \\
17\end{array}$ & $\begin{array}{r}\mathbf{0 . 1 1 5} \\
(0.043) \\
0.007 \\
{[0.282,0.994]} \\
2432 \\
33 \\
64 \\
\end{array}$ \\
\hline $\mathrm{N}$ total & 1856 & 2445 & 2529 \\
\hline
\end{tabular}

Notes: Standard errors were bootstrapped with $B=1,999$ replications.

\section{Education}

Table 8 considers differences in the effect size depending on the self-employed persons' education level, distinguishing between persons with university degree and without. The results show that the average increase in survival probability due to the emergency aid program has a strong and significant effect of 7.0 percentage points among the selfemployed with university degree, but no effect among persons without such degree. The reason could pertain to the marginal utility that the self-employed persons in the two subgroups derive from the lump sum payment. Stasielowicz (2020) shows that the ability to adapt to unforeseen shocks increases with the level of education. Applied to this context, it could mean that better educated people, also because they are more often opportunity driven (Simón-Moya et al. 2016), could be better able to come up with ideas on how to restructure their venture to weather the crisis, with the lump sum payment maybe also allowing to finance investments.

Table 8: ATT by education level

\begin{tabular}{|c|c|c|}
\hline \multicolumn{3}{|c|}{ Education } \\
\hline & university degree & no university degree \\
\hline ATT & 0.070 & 0.000 \\
\hline SE & $(0.031)$ & $(0.040)$ \\
\hline p-value & 0.025 & 0.999 \\
\hline common support & {$[0.208,0.996]$} & {$[0.313,0.992]$} \\
\hline $\mathrm{N}$ matched & 3895 & 2455 \\
\hline N unmatched & 22 & 364 \\
\hline N out of common support & 50 & 44 \\
\hline $\mathrm{N}$ total & 3967 & 2863 \\
\hline
\end{tabular}

Notes: Standard errors were bootstrapped with $B=1,999$ replications. 


\section{Industries}

The impact of the government measures to contain the pandemic marked industries heterogeneously, with some industries, like the events, restaurants, and tourism being particularly affected, e.g., by the thresholds for the number of people gathering together. These industries suffered from revenue declines more strongly than others (see Table 1), which might increase the marginal utility of the emergency aid. Therefore, we explore heterogeneous treatment effects between industries and estimate the average treatment effect within the particularly affected industries - under which we subsume hotels and restaurants as well as arts, recreation, and cultural activities -- against less affected industries, comprising manufacturing, repairing of motor vehicles, trade, information and communications, professional services, education, health and social care, and other services. The results are listed in Table 9.

On average, the emergency aid increased the subjective survival probability of the self-employed in strongly affected industries by 12.8 percentage points, whereas the survival probability in the other industries was - on average - unaffected. Note, however, that the reference category is quite heterogeneous. Therefore, an insignificant overall effect does not mean that a single industry within this category did not benefit from the emergency fund. Limits in the sample size preclude a more detailed analysis of the remaining industries. From a policy perspective, the support program appears to have been welltargeted in the sense that it predominantly improved the subjective survival probability for those self-employed whose sectors were particularly hard hit by the crisis.

Table 9: ATT by industry

\begin{tabular}{|l|r|r|}
\hline \multicolumn{3}{|c|}{ Industries } \\
\hline \multicolumn{2}{|c|}{$\begin{array}{c}\text { particularly affected by } \\
\text { the crisis }\end{array}$} & less affected \\
\hline ATT & 0.128 & 0.016 \\
\hline SE & $(0.030)$ & $(0.036)$ \\
p-value & 0.000 & 0.663 \\
common support & {$[0.215,0.994]$} & $0.305,0.995]$ \\
N matched & 3217 & 3024 \\
N unmatched & 104 & 391 \\
N out of common support & 39 & 55 \\
\hline N total & 3360 & 3470 \\
\hline
\end{tabular}

Notes: Standard errors were bootstrapped with $B=1,999$ replications. Particularly affected industries: hotels and restaurants, arts, recreation, and cultural activities. Less affected industries: manufacturing, repairing of vehicles, trade, information and communications, professional services, education, health and social care, other services. 


\subsubsection{Timing of the application process}

\section{Application processing speed}

We also investigate the role of timing, i.e. whether temporal aspects in processing and disbursing the emergency aid influence the effect on subjective survival probability. First, we consider how the application processing speed influenced the effect among the treated individuals and sort the treated individuals into two groups: (i) those whose applications were processed within 5 days (compared to an average application processing speed of 7.5 days, see Section 3.5, Table 2), which we denote as fast, and (ii) those waiting for more than 5 days for their applications to be processed, which we denote as slow. The results are listed in Table 10. For the self-employed whose applications were processed fast, the subjective survival probability increased by 5.8 percentage points on average, while we find no significant effect for individuals whose applications were processed slowly. It appears that the financial situation of the self-employed was time sensitive and that the speed at which the aid was granted has a measurable impact on the subjective survival probability.

Table 10: ATT by application processing speed

\begin{tabular}{|l|r|r|}
\hline \multicolumn{2}{|c|}{ Application processing speed } \\
\hline \multicolumn{2}{|c|}{$\begin{array}{c}\text { fast } \\
\text { (up to 5 days) }\end{array}$} & $\begin{array}{c}\text { slow } \\
\text { (more than 5 days) }\end{array}$ \\
\hline ATT & 0.058 & 0.016 \\
\hline SE & $(0.030)$ & 0.024 \\
p-value & 0.057 & 0.508 \\
common support & {$[0.039,0.995]$} & {$[0.110,0.982]$} \\
N matched & 4541 & 3057 \\
N unmatched & 0 & 0 \\
N out of common support & 34 & 40 \\
\hline N total & 4575 & 3097 \\
\hline
\end{tabular}

Notes: Standard errors were bootstrapped with $B=1,999$ replications. The total number of observations after summing across the subsamples exceed the numbers from the main sample $(N=6,830)$ since the subsamples are not mutually exclusive. While the treated individuals are uniquely allocated to the subsamples, the control group in each subsample comprises all individuals who plan to apply for the support program.

\section{Elapsed time since granting}

We further explore differences in the subjective survival probability depending on the time that has elapsed since the aid was granted. Table 11 compares the ATT for self-employed answering the survey one, two, three, and more than four weeks after the date of approval. It shows that the effect vanishes with time: immediately after the approval, receiving the aid triggers a certain optimism that translates into an increase in the subjective survival 
probability of 11.2 percentage points, while the effect reduces to 8.3 percentage points after one week and becomes insignificant after more than two weeks. The results suggest that the program did not have a lasting effect on the financial situation of the self-employed, probably because it consisted of a one-time payment while the financial difficulties caused by the lockdown persisted.

Table 11: ATT by elapsed time since granting

\begin{tabular}{|c|c|c|c|c|}
\hline \multicolumn{5}{|c|}{ Time elapsed since aid was granted } \\
\hline & up to 7 days & 8 to 14 days & 15 to 21 days & more than 21 days \\
\hline ATT & 0.112 & 0.083 & 0.018 & 0.019 \\
\hline SE & $(0.030)$ & $(0.026)$ & $(0.028)$ & $(0.028)$ \\
\hline p-value & 0.000 & 0.002 & 0.526 & 0.497 \\
\hline common support & {$[0.031,0.865]$} & {$[0.107,0.980]$} & {$[0.056,0.993]$} & {$[0.040,0.991]$} \\
\hline $\mathrm{N}$ matched & 1592 & 2484 & 2580 & 2765 \\
\hline N unmatched & 17 & 9 & 0 & 0 \\
\hline $\mathrm{N}$ out of common support & 36 & 33 & 16 & 23 \\
\hline $\mathrm{N}$ total & 1645 & 2526 & 2596 & 2788 \\
\hline
\end{tabular}

Notes: Standard errors were bootstrapped with $B=1,999$ replications. The total number of observations after summing across the subsamples exceed the numbers from the main sample $(N=6,830)$ since the subsamples are not mutually exclusive. While the treated individuals are uniquely allocated to the subsamples, the control group in each subsample comprises all individuals who plan to apply for the support program.

\subsection{Robustness Checks}

\subsubsection{Nearest-Neighbor-Matching}

To verify whether our results are sensitive to the choice of the matching algorithm, we repeat the analysis with a propensity score based on nearest-neighbor-matching with two neighbors and replacement. The results are listed in Table 12, columns (1) and (2), and are quite similar to those obtained under the Epanechnikov kernel estimator both in terms of size effect and efficiency. ${ }^{9}$ The average treatment effect amounts to 4.2 percentage points against 4.5 percentage points in the main analysis, and the average treatment effect of the treated is 4.3 percentage points with nearest-neighbor matching against 4.4 percentage points in the main analysis. Apparently, using more observations from the control group as matching partners under the kernel estimator marginally increases efficiency without biasing the results. Imposing a caliper of 0.05 does not result in any further bias reduction but leads to a higher variance since the number of potential matching partners is reduced (Table 12, columns (3) and (4)).

\footnotetext{
${ }^{9}$ We calculate analytical standard errors following Abadie and Imbens (2016) since Abadie and Imbens (2008) show that bootstrapping does not provide consistent standard errors in the case of nearest-neighbor matching with a fixed number of neighbors and replacement. Note that trimming is less relevant with nearest-neighbor matching since only the two closest observations are used, whereas kernel matching also uses information from faraway control units, depending on the bandwidth chosen.
} 
Table 12: Nearest-Neighbor-Matching with two neighbors and replacement

\begin{tabular}{|l|r|r|r|r|}
\hline \multicolumn{4}{|c|}{ NN2-Matching } \\
\hline & \multicolumn{2}{c|}{ without trimming } & \multicolumn{2}{c|}{ Caliper 0.05 } \\
\hline treatment effect & 0.042 & 0.043 & 0.043 & ATT \\
\hline SE & $(0.021)$ & $(0.023)$ & $(0.022)$ & 0.041 \\
\hline p-value & 0.048 & 0.059 & 0.049 & 0.083 \\
$\mathbf{N}$ matched & 6830 & 6830 & 6820 & 6820 \\
N out of common support & 0 & 0 & 10 & 10 \\
\hline N total & 6830 & 6830 & 6830 & 6830 \\
\hline
\end{tabular}

Notes: Robust standard errors were estimated following Abadie and Imbens (2016).

\subsubsection{Ordinal outcome variable}

The original outcome variable that we use to measure the subjective survival probability is an ordinal variable ranging from 1 ("very unlikely") to 5 (very likely"). In the main analysis, we recode the variable to obtain a binary variable that can be directly interpreted as probability by setting categories 5 ("very likely") and 4 ("rather likely") equal to one, and the remaining categories 3 ("neutral"), 2 ("rather unlikely"), and 1 ("very unlikely") equal to zero (see Section 4.2). To verify whether the results are sensitive to the definition of the binary variable, we re-estimate the treatment effects with the original variable. The results are listed in Table 13, showing a robust positive effect both for the ATE and the ATT. However, the interpretation of the magnitudes is less intuitive, as receiving financial support from the emergency fund increases the survival perception by 0.148 units on average on a scale from 1 to 5 . Since the ordinal variable contains more variation across individuals, the treatment effects are more efficiently estimated, supporting our conclusion that the emergency program had a measurable effect on the self-employed persons' occupational survival probability, even though the magnitude of the effect was moderate. Table 15 in the appendix lists the results for the heterogeneity analysis, which are in line with the binary model.

Table 13: Ordinal outcome variable

\begin{tabular}{|c|c|c|}
\hline \multicolumn{3}{|c|}{ Ordinal outcome variable } \\
\hline & ATE & ATT \\
\hline treatment effect & 0.146 & 0.148 \\
\hline SE & $(0.053)$ & $(0.059)$ \\
\hline p-value & 0.006 & 0.012 \\
\hline common support & {$[0.241,0.998]$} & {$[0.241,0.998]$} \\
\hline $\mathrm{N}$ matched & 6766 & 6766 \\
\hline $\mathrm{N}$ unmatched & 43 & 43 \\
\hline $\mathrm{N}$ out of common support & 21 & 21 \\
\hline $\mathrm{N}$ total & 6830 & 6830 \\
\hline
\end{tabular}

Notes: Standard errors were bootstrapped with $B=1,999$ replications. The propensity score was estimated with the Epanechnikov kernel matching algorithm applying the min-max trimming criterion. The outcome variable is the subjective probability to stay self-employed during the next 12 months coded as 1 ("very unlikely"), 2 ("likely"), 3 ("neutral"), 4 ("likely"), and 5 ("very likely"). 


\section{Discussion, Limitations, and Conclusions}

The COVID-19 pandemic and the related government-mandated lock-down measures affected the self-employed severely. As there were no existing support measures available, many countries - including Germany - implemented on short notice financial support programs designed to help the self-employed survive the corona crisis. In this paper, we investigate the impact of the German emergency aid program for which $€ 50 \mathrm{bn}$ was budgeted and $€ 13.7 \mathrm{bn}$ spent. The program was launched at the end of March 2020 and was accessible for the following two months with the self-employed able to apply for a one-off lump-sum payment of up to $€ 15,000$ to cover venture-related operating costs. In this study, we provide first evidence on the effectiveness of this program. For our analysis, we took advantage of a real-time online survey that was answered by more than 20,000 selfemployed individuals between April 7 and May 4, 2020, which captured a rich set of information on variables that influence the selection into the treatment as well as the outcome variable, namely the subjective survival probability. We use these data to implement a propensity matching approach and compare self-employed who received the grant with those self-employed who planned to apply for this financial support.

First of all, we observe that the applicants suffered considerable and higher monthly financial losses than the non-applicants and lost a higher proportion of their revenue. In this respect, the emergency aid program seems to be well targeted. Furthermore, we find that the emergency aid program had moderate effects on the subjective probability to remain self-employed in the subsequent months, with these positive effects appearing to be stronger in those industries that were particularly affected by the crisis, like the event industry, restaurants, and the tourism industry. We further reveal important heterogeneity effects in the sense that stronger positive effects were observed among individuals who were more risk tolerant and among higher educated self-employed, while it had no significant effects among the self-employed with lower risk tolerance and among those with education levels below a university degree. The latter results could be interpreted in the sense that the more risk tolerant as well as the better educated self-employed were more willing and more confident to make productive use of the financial support, thus also possessing the cognitive skills needed to do so.

We also observe effects that are informative for the future design of such policy instruments. Our real-time online survey allows for investigating the impact of the speed of processing the application as well as how long the positive effect lasted among the surveyed individuals. We observe that the speed in granting applications has a significant 
impact on how helpful the financial support is perceived by the recipients. Support granted within five days had a significant effect, while payments granted with more delay did not. Furthermore, the positive effect of the financial support remained significant only for the first two weeks after it was paid out; payments from the emergency aid fund that dated back more than two weeks did not significantly affect anymore how the self-employed felt about their prospects.

These observations are highly relevant for the further design of such policy instruments and have three important implications: First, the program was moderately effective in helping the self-employed get through the crisis. It increased their subjective survival probability and, hence, their optimism to master the difficult situation. The fact that it helped some specific groups more than others may point to limitations in the use of financial aid. As the payments could only be used to cover fixed business expenses, we speculate that effects might have been stronger over all groups if the lump sum payment could have been used for covering living expenses (as was the case in various other economies, see Tenhagen 2020). Second, the observation that the positive effect faded relatively quickly allows for the interpretation that more lasting effects could have been unleashed if the one-off lump sum payment would have been replaced with monthly payments. Third, many evaluation studies include descriptive analyses regarding the admission process of state-financed support instruments without being able to draw any larger conclusions. The analysis of our real-time data set reveals that the speed of the process is key to the success of this financial support instrument. It clarifies how important it is to have a well-prepared administrative structure that is able to process a large number of applications in a relatively short period of time.

Concluding we should emphasize the main challenge of this paper, which also reflects its limitation. Having been able to work with such a large real-time dataset, it remains to be cross-sectional. Ideally, a panel data on self-employed would have given us the econometrical leverage to estimate the emergency aid effects in more detail, in the long run, and give us the possibility to match subjective and objective measures. That being said, we would also have liked to use a more objective outcome measure. However, at this stage, we are only able to use subjective survival probabilities as the COVID-19 crisis is still ongoing and it remains widely unclear when an objective measure could be introduced to evaluate such programs. Thus, introducing subjective survival probabilities is, at this stage, the second-best solution that has its own advantages. It also allows investigating how the speed of an admission process influences such subjective probabilities and informs the government under what conditions recipients of financial support out of the emergency aid program perceive such support as helpful and are optimistic about their future as entrepreneurs. After all, following Ludwig Erhard, former German Minister of Economics and father of the German "Wirtschaftswunder", the economy is to a large extent about psychology. 


\section{References}

Abadie, A., Imbens, G. (2008). On the failure of the bootstrap for matching estimators. Econometrica 76(6) 1537-1557.

Abadie, A., Imbens, G. (2016). Matching on the estimated propensity score. Econometrica 84(2) 781-807.

Acs, Z., Åstebro, T., Audretsch, D., \& Robinson, D. T. (2016). Public policy to promote entrepreneurship: a call to arms. Small Business Economics, 47(1), 35-51.

Adams-Prassl, A., T. Boneva, M. Golin, and C. Rauh (2020). Inequality in the impact of the coronavirus shock: Evidence from real time surveys. Journal of Public Economics 189.

Audretsch, D.B; A.S. Kritikos, and A. Schiersch (2020). Micro firms and innovation in the service sector. Small Business Economics 55, 997-1018.

Bartik, A., M. Bertrand, Z. Cullen, E. L. Glaeser, M. Luca, and C. Stanton (2020). How are small businesses adjusting to COVID-19? Early evidence from a survey. Becker Friedman Institute for Economics Working Paper 2020-42, University of Chicago.

Beland, 1._P., Fakorede, O., and D. Mikola (2020). The short-term effect of COVID-19 on self-employed workers in Canada. Technical report, 2020.

Bendell, B., Sullivan, D. \& Marvel, M. (2019). A gender-aware study of self-leadership strategies among high-growth entrepreneurs. Journal of Small Business Management 57 (1), 110-130.

Bertschek, Irene und Daniel Erdsiek (2020), Soloselbstständigkeit in der Corona-Krise, Digitalisierung hilft bei der Bewältigung der Krise, ZEW-Kurzexpertise Nr. 2008, Mannheim

Block, J.H.; C. Fisch, and M. Hirschmann (2020): Solo self-employed and bootstrap financing in the COVID-19 crisis, forthcoming in Small Business Economics.

Blundell, J. and S. Machin (2020). Self-employment in the COVID-19 crisis. Working Paper 3, Centre of Economic Performance.

Cahuc, P. (2014). Short-time work compensation schemes and employment, IZA World of Labor 11.

Cassar, G. (2010). Are individuals entering self-employment overly optimistic? An empirical test of plans and projections on nascent entrepreneur expectations. Strategic Management Journal, 31(8), 822-840.

Caliendo, M., Fossen, F., \& Kritikos, A.S. (2010). The impact of risk attitudes on entrepreneurial survival. Journal of Economic Behavior \& Organization 76(1) 4563.

Caliendo, M., Fossen, F. \& Kritikos, A.S. (2014). Personality characteristics and the decisions to become and stay self-employed. Small Business Economics 42, 787814.

Caliendo, M. \& Kopeining, S. (2008). Some practical guidance for the implementation of propensity score matching. Journal of Economic Surveys 22(1) 31-72.

Caliendo, M. \& Kuenn, S. (2011): Start-up subsidies for the unemployed: Long-term evidence and effect heterogeneity, Journal of Public Economics 95(3-4), 311-331.

Caliendo, M. Kuenn, S. \& Weissenberger, M (2016): Personality traits and the evaluation of start-up subsidies, European Economic Review 86, 87-108. 
Crossley, T.F., Fisher, P., Low, H (2021): The heterogeneous and regressive consequences of COVID-19: Evidence from high quality panel data. Journal of Public Economics, 193(1).

Dohmen, T., Falk, A., Huffman, D., Sunde, U., Schupp, J., \& Wagner, G. (2011): Individual risk attitudes: measurement, determinants, and behavioral consequences. Journal of the European Economic Association 9(3), 522-550.

de Vries, N., Liebregts, W., \& van Stel, A. (2019). Explaining entrepreneurial performance of solo self-employed from a motivational perspective. Small Business Economics, 1-14.

Fairlie, R.W. (2020). The impact of COVID-19 on small business owners: The first three months after social-distancing restrictions, Journal of Economics and Management Strategy 29(4) 727-740.

Federal Ministry for Economic Affairs and Energy (2020). German government announces 50 billion in emergency aid for small businesses. https://www.bmwi.de/Redaktion/ EN/Pressemitteilungen/2020/20200323-50german-government-announces-50-billion-euros-in-emergency-aid-for-smallbusinesses.html, accessed 2020-10-05.

Fredriksson, P. and Johannsson, P. (2008). Dynamic treatment assignment - The consequences for evaluations using observational data. Journal of Business \& Economic Statistics 26(4) 435-445.

Fritsch, M., Brixy, U., \& Falck, O. (2006). The effect of industry, region, and time on new business survival- A multi-dimensional analysis. Review of Industrial Organization 28(3) 285-306.

Gimeno, J., Folta, T. B., Cooper, A. C., \& Woo, C. Y. (1997). Survival of the fittest? Entrepreneurial human capital and the persistence of underperforming firms. Administrative Science Quarterly 42(4) 750-783.

Graeber, D., Kritikos, A.S., \& Seebauer, J. (2020). COVID-19: A crisis of the female self-employed, DIW Berlin, Discussion Paper \# 1903.

Hartog, J., Van Praag, M., \& Van Der Sluis, J. (2010). If you are so smart, why aren't you an entrepreneur? Returns to cognitive and social ability: entrepreneurs versus employees. Journal of Economics \& Management Strategy 19(4) 947-989.

Holtz-Eakin, D., Joulfaian, D., \& Rosen, H. S. (1994). Sticking it out: entrepreneurial survival and liquidity constraints. Journal of Political Economy 102(1) 53-75.

Hurst, E., \& Lusardi, A. (2004). Liquidity constraints, household wealth, and entrepreneurship. Journal of Political Economy, 112(2), 319-347.

Hyytinen, A., Lahtonen, J., \& Pajarinen, M. (2014). Forecasting errors of new venture survival. Strategic Entrepreneurship Journal, 8(4), 283-302.

IfW (2020). Economic Outlook Update: German GDP expected to slump between 4.5 and 9 percent in 2020. https://www.ifw-kiel.de/publications/mediainformation/2020/economic-outlook-update-german-gdp-expected-to-slumpbetween-45-and-9-percent-in-2020/ (accessed 14 April 2020).

Kalenkoski, C. M. and S. W. Pabilonia (2020). Initial impact of the COVID-19 pandemic on the employment and hours of self-employed coupled and single workers by gender and parental status. IZA Discussion Paper 13443, Bonn.

Kato, M., \& Honjo, Y. (2015). Entrepreneurial human capital and the survival of new firms in high-and low-tech sectors. Journal of Evolutionary Economics 25(5) 925957.

Kautonen, T., Down, S., \& Minniti, M. (2014). Ageing and entrepreneurial preferences. Small Business Economics 42(3) 579-594. 
Kritikos, A.S., D. Graeber, and J. Seebauer (2020). Corona-Pandemie wird zur Krise fuer Selbstaendige. DIW aktuell 47.

Minniti, M. (2008). The role of government policy on entrepreneurial activity: productive, unproductive, or destructive? Entrepreneurship Theory and Practice, 32(5), 779-790.

Parker, S. C., \& Van Praag, C. M. (2006). Schooling, capital constraints, and entrepreneurial performance: The endogenous triangle. Journal of Business \& Economic Statistics 24(4) 416-431.

Raffiee, J. \& Feng, J. (2014). Should I quit my day job? A hybrid path to entrepreneurship Academy of Management Journal 57 (4) 936-963.

Rosenbaum, P. and Rubin, D. (1985). Constructing a control group using multivariate matched sampling methods that incorporate the propensity score. The American Statistician 39(1) 33-38.

Roy, A. (1951). Some thoughts on the distribution of earnings. Oxford Economic Papers 3(2) 135-145.

Rubin, D. (1974). Estimating causal effects to treatments in randomized and nonrandomized studies. Journal of Educational Psychology 66(5) 688-701.

Rubin, D. (2001). Using propensity scores to help design observational studies: application to the tobacco litigation. Health Services \& Outcomes Research Methodology 2(3-4) 169-188.

Sianesi, B. (2004). An evaluation of the Swedish system of active labor market programs in the 1990s The Review of Economics and Statistics 89(1) 133-155.

Simón-Moya, V., Revuelto-Taboada, L., \& Ribeiro-Soriano, D. (2016). Influence of economic crisis on new SME survival: reality or fiction? Entrepreneurship and Regional Development 28(1): 157-176

Sorgner, A., Fritsch, M. \& Kritikos, A.S. (2017): Do entrepreneurs really earn less? Small Business Economics 49(2), 251-272.

Stasielowicz, L. (2020). How important is cognitive ability when adapting to changes? A meta-analysis of the performance adaptation literature. Personality and Individual Differences 166(1) 110-178.

Tenhagen, H.-J. (2020). Diese Hilfen gibt es noch für Solo-Selbständige, Der Spiegel, May 16.

Van der Sluis, J., Van Praag, M., \& Vijverberg, W. (2008). Education and entrepreneurship selection and performance: a review of the empirical literature. Journal of Economic Surveys 22(5) 795-841. 


\section{Appendix}

Table 14: Summary statistics

\begin{tabular}{|c|c|c|c|c|c|c|c|c|}
\hline \multirow{2}{*}{\begin{tabular}{|l|} 
Variables and categories \\
\end{tabular}} & \multicolumn{2}{|c|}{$\begin{array}{l}\text { Whole } \\
\text { Sample }\end{array}$} & \multicolumn{2}{|c|}{$\begin{array}{l}\text { Matched } \\
\text { sample }\end{array}$} & \multicolumn{2}{|c|}{$\begin{array}{c}\text { Treatment } \\
\text { sample }\end{array}$} & \multicolumn{2}{|c|}{$\begin{array}{l}\text { Control } \\
\text { Sample }\end{array}$} \\
\hline & $\%$ & $\mathrm{~N}$ & $\%$ & $\mathrm{~N}$ & $\%$ & $\mathrm{~N}$ & $\%$ & $\mathrm{~N}$ \\
\hline Risk tolerance & & & & & & & & \\
\hline High risk tolerance & $35 \%$ & 6,030 & $37 \%$ & 2529 & $38 \%$ & 2198 & $32 \%$ & 331 \\
\hline Medium risk tolerance & $36 \%$ & 6,086 & $36 \%$ & 2445 & $36 \%$ & 2075 & $36 \%$ & 370 \\
\hline Low risk tolerance & $29 \%$ & 4,974 & $27 \%$ & 1856 & $26 \%$ & 1530 & $32 \%$ & 326 \\
\hline \multicolumn{9}{|l|}{ Monthly living costs (in $€$ ) } \\
\hline Up to 500 & $2 \%$ & 423 & $1 \%$ & 87 & $1 \%$ & 60 & $3 \%$ & 27 \\
\hline 501 to 1,000 & $16 \%$ & 2,681 & $14 \%$ & 950 & $14 \%$ & 787 & $16 \%$ & 163 \\
\hline 1,001 to 1,500 & $26 \%$ & 4,369 & $26 \%$ & 1750 & $26 \%$ & 1503 & $24 \%$ & 247 \\
\hline 1,501 to 2,000 & $22 \%$ & 3,834 & $24 \%$ & 1630 & $24 \%$ & 1420 & $20 \%$ & 210 \\
\hline 2,001 to 2,500 & $14 \%$ & 2,376 & $15 \%$ & 1003 & $15 \%$ & 859 & $14 \%$ & 144 \\
\hline 2,501 to 3,000 & $8 \%$ & 1,440 & $9 \%$ & 614 & $9 \%$ & 521 & $9 \%$ & 93 \\
\hline 3,001 to 3,500 & $5 \%$ & 779 & $5 \%$ & 328 & $5 \%$ & 269 & $6 \%$ & 59 \\
\hline 3,501 to 4,000 & $3 \%$ & 458 & $3 \%$ & 184 & $3 \%$ & 146 & $4 \%$ & 38 \\
\hline 4,001 to 4,500 & $1 \%$ & 214 & $1 \%$ & 102 & $2 \%$ & 90 & $1 \%$ & 12 \\
\hline 4,501 to 5,000 & $2 \%$ & 282 & $1 \%$ & 101 & $1 \%$ & 82 & $2 \%$ & 19 \\
\hline More than 5,000 & $1 \%$ & 234 & $1 \%$ & 81 & $1 \%$ & 66 & $1 \%$ & 15 \\
\hline \multicolumn{9}{|l|}{ Sales decline due to pandemic } \\
\hline No decline or increase & $2 \%$ & 307 & $0 \%$ & 31 & $0 \%$ & 15 & $2 \%$ & 16 \\
\hline Up to $25 \%$ & $6 \%$ & 953 & $3 \%$ & 203 & $3 \%$ & 154 & $5 \%$ & 49 \\
\hline $26 \%$ to $50 \%$ & $13 \%$ & 2,174 & $10 \%$ & 690 & $9 \%$ & 527 & $16 \%$ & 163 \\
\hline $51 \%$ to $75 \%$ & $17 \%$ & 2,900 & $17 \%$ & 1154 & $17 \%$ & 977 & $17 \%$ & 177 \\
\hline $76 \%$ to $99 \%$ & $25 \%$ & 4,205 & $28 \%$ & 1940 & $29 \%$ & 1677 & $26 \%$ & 263 \\
\hline $100 \%$ & $38 \%$ & 6,551 & $41 \%$ & 2812 & $42 \%$ & 2453 & $35 \%$ & 359 \\
\hline \multicolumn{9}{|l|}{ Estimated time to insolvency } \\
\hline No separate business account & $26 \%$ & 4,437 & $25 \%$ & 1690 & $24 \%$ & 1418 & $26 \%$ & 272 \\
\hline Already insolvent & $10 \%$ & 1,627 & $9 \%$ & 628 & $10 \%$ & 560 & $7 \%$ & 68 \\
\hline One month & $16 \%$ & 2,776 & $19 \%$ & 1284 & $19 \%$ & 1103 & $18 \%$ & 181 \\
\hline Two months & $16 \%$ & 2,654 & $17 \%$ & 1177 & $17 \%$ & 1007 & $17 \%$ & 170 \\
\hline Three months & $15 \%$ & 2,513 & $16 \%$ & 1069 & $16 \%$ & 909 & $16 \%$ & 160 \\
\hline Four to six months & $12 \%$ & 2,022 & $11 \%$ & 741 & $11 \%$ & 610 & $13 \%$ & 131 \\
\hline $\begin{array}{l}\text { More than } 6 \text { months } \\
\text { Gender }\end{array}$ & $6 \%$ & 1,061 & $4 \%$ & 241 & $3 \%$ & 196 & $4 \%$ & 45 \\
\hline$\overline{\text { Male }}$ & $48 \%$ & 8200 & $52 \%$ & 3557 & $52 \%$ & 3036 & $51 \%$ & 521 \\
\hline Female & $52 \%$ & 8811 & $48 \%$ & 3247 & $47 \%$ & 2750 & $48 \%$ & 497 \\
\hline Diverse & $1 \%$ & 79 & $0 \%$ & 26 & $0 \%$ & 17 & $1 \%$ & 9 \\
\hline \multicolumn{9}{|l|}{ Age } \\
\hline Up to 39 years & $22 \%$ & 3,803 & $24 \%$ & 1611 & $24 \%$ & 1364 & $24 \%$ & 247 \\
\hline 40 to 49 years & $28 \%$ & 4,769 & $28 \%$ & 1938 & $29 \%$ & 1659 & $27 \%$ & 279 \\
\hline 50 to 59 years & $37 \%$ & 6,298 & $36 \%$ & 2470 & $36 \%$ & 2110 & $35 \%$ & 360 \\
\hline 60 years and more & $13 \%$ & 2,220 & $12 \%$ & 811 & $12 \%$ & 670 & $14 \%$ & 141 \\
\hline \multicolumn{9}{|l|}{ Education } \\
\hline$\overline{\text { Other }}$ & $21 \%$ & 3,584 & $22 \%$ & 1528 & $23 \%$ & 1337 & $19 \%$ & 191 \\
\hline Professional education & $18 \%$ & 3,087 & $20 \%$ & 1335 & $20 \%$ & 1164 & $17 \%$ & 171 \\
\hline University degree & $61 \%$ & 10,419 & $58 \%$ & 3967 & $57 \%$ & 3302 & $65 \%$ & 665 \\
\hline \multicolumn{9}{|l|}{ Federal state } \\
\hline Baden-Württemberg & $10 \%$ & 1,642 & $10 \%$ & 715 & $10 \%$ & 577 & $13 \%$ & 138 \\
\hline Bavaria & $17 \%$ & 2,843 & $9 \%$ & 630 & $8 \%$ & 470 & $16 \%$ & 160 \\
\hline Berlin & $11 \%$ & 1,852 & $19 \%$ & 1313 & $22 \%$ & 1252 & $6 \%$ & 61 \\
\hline Brandenburg & $3 \%$ & 439 & $2 \%$ & 156 & $2 \%$ & 139 & $2 \%$ & 17 \\
\hline
\end{tabular}




\begin{tabular}{|c|c|c|c|c|c|c|c|c|}
\hline Bremen & $1 \%$ & 144 & $0 \%$ & 31 & $0 \%$ & 23 & $1 \%$ & 8 \\
\hline Hamburg & $5 \%$ & 914 & $6 \%$ & 433 & $6 \%$ & 354 & $8 \%$ & 79 \\
\hline Hesse & $8 \%$ & 1,344 & $6 \%$ & 411 & $5 \%$ & 303 & $11 \%$ & 108 \\
\hline Mecklenburg-Western Pomerania & $1 \%$ & 203 & $1 \%$ & 49 & $1 \%$ & 42 & $1 \%$ & 7 \\
\hline Lower Saxony & $8 \%$ & 1,295 & $6 \%$ & 379 & $5 \%$ & 299 & $8 \%$ & 80 \\
\hline North Rhine-Westphalia & $21 \%$ & 3,544 & $29 \%$ & 1978 & $31 \%$ & 1780 & $19 \%$ & 198 \\
\hline Rhineland Palatinate & $4 \%$ & 741 & $2 \%$ & 152 & $2 \%$ & 92 & $6 \%$ & 60 \\
\hline Saarland & $1 \%$ & 103 & $0 \%$ & 26 & $0 \%$ & 20 & $1 \%$ & 6 \\
\hline Saxony & $5 \%$ & 889 & $4 \%$ & 277 & $4 \%$ & 233 & $4 \%$ & 44 \\
\hline Saxony-Anhalt & $1 \%$ & 252 & $1 \%$ & 54 & $1 \%$ & 43 & $1 \%$ & 11 \\
\hline Schleswig-Holstein & $3 \%$ & 590 & $2 \%$ & 142 & $2 \%$ & 107 & $3 \%$ & 35 \\
\hline Thuringia & $2 \%$ & 295 & $1 \%$ & 84 & $1 \%$ & 69 & $1 \%$ & 15 \\
\hline \multicolumn{9}{|l|}{ Duration of self-employment } \\
\hline 0 to 4 years & $19 \%$ & 3,309 & $17 \%$ & 1151 & $17 \%$ & 964 & $18 \%$ & 187 \\
\hline 5 to 10 years & $25 \%$ & 4,254 & $24 \%$ & 1663 & $25 \%$ & 1427 & $23 \%$ & 236 \\
\hline 11 to 20 years & $33 \%$ & 5,648 & $34 \%$ & 2345 & $34 \%$ & 1984 & $35 \%$ & 361 \\
\hline 21 to 30 years & $17 \%$ & 2,927 & $19 \%$ & 1292 & $19 \%$ & 1104 & $18 \%$ & 188 \\
\hline $\begin{array}{l}\text { More than } 30 \text { years } \\
\text { Industrv cateaory }\end{array}$ & $6 \%$ & 952 & $6 \%$ & 379 & $6 \%$ & 324 & $5 \%$ & 55 \\
\hline Manufacturing & $6 \%$ & 982 & $6 \%$ & 397 & $6 \%$ & 334 & $6 \%$ & 63 \\
\hline Trade; repair of motor vehicles & $2 \%$ & 425 & $2 \%$ & 162 & $3 \%$ & 152 & $1 \%$ & 10 \\
\hline Accommodation and food service & $2 \%$ & 329 & $3 \%$ & 172 & $3 \%$ & 162 & $1 \%$ & 10 \\
\hline Information and communication & $12 \%$ & 2,063 & $10 \%$ & 661 & $9 \%$ & 538 & $12 \%$ & 123 \\
\hline Professional services & $7 \%$ & 1,277 & $6 \%$ & 405 & $6 \%$ & 325 & $8 \%$ & 80 \\
\hline Other service activities & $5 \%$ & 933 & $4 \%$ & 246 & $3 \%$ & 191 & $5 \%$ & 55 \\
\hline Education & $12 \%$ & 2,054 & $11 \%$ & 782 & $11 \%$ & 651 & $13 \%$ & 131 \\
\hline Human health and social work act. & $8 \%$ & 1,284 & $6 \%$ & 439 & $6 \%$ & 355 & $8 \%$ & 84 \\
\hline Arts, entertainment and recreation & $41 \%$ & 7,006 & $48 \%$ & 3298 & $50 \%$ & 2875 & $41 \%$ & 423 \\
\hline Other & $4 \%$ & 737 & $4 \%$ & 268 & $4 \%$ & 220 & $5 \%$ & 48 \\
\hline \multirow{2}{*}{\multicolumn{9}{|c|}{$\frac{\text { Level of digitization }}{\text { (continuous scale from } 1 \text { to } 5 \text { ) }}$}} \\
\hline & & & & & & & & \\
\hline Mean (std. dev) & 2.89 & (1.18) & 2.84 & $(1.16)$ & 2.87 & $(1.14)$ & 2.86 & (1.14) \\
\hline \multicolumn{9}{|l|}{ Part-time/full-time self-employed } \\
\hline Part-time & $11 \%$ & 1,845 & $5 \%$ & 318 & $4 \%$ & 206 & $11 \%$ & 112 \\
\hline Full time & $89 \%$ & 15,245 & $95 \%$ & 6512 & $96 \%$ & 5597 & $89 \%$ & 915 \\
\hline \multicolumn{9}{|l|}{ Solo self-employed } \\
\hline No & $21 \%$ & 3,598 & $24 \%$ & 1640 & $24 \%$ & 1417 & $22 \%$ & 223 \\
\hline Yes & $79 \%$ & 13,492 & $76 \%$ & 5190 & $76 \%$ & 4386 & $78 \%$ & 804 \\
\hline \multirow{2}{*}{\multicolumn{9}{|c|}{$\frac{\text { Application for basic security }}{\text { ("Hartz IV") }}$}} \\
\hline & & & & & & & & \\
\hline Not applied & $92 \%$ & 15,763 & $92 \%$ & 6274 & $91 \%$ & 5282 & $97 \%$ & 992 \\
\hline Applied & $7 \%$ & 1,225 & $8 \%$ & 531 & $9 \%$ & 505 & $3 \%$ & 26 \\
\hline Already paid out & $1 \%$ & 102 & $0 \%$ & 25 & $0 \%$ & 16 & $1 \%$ & 9 \\
\hline
\end{tabular}


Table 15: Heterogeneity analysis with ordinal outcome variable

\begin{tabular}{|c|c|c|c|}
\hline & \multicolumn{3}{|c|}{ Ordinal outcome variable } \\
\hline & ATT & SE & $\mathrm{N}$ matched \\
\hline \multicolumn{4}{|l|}{ risk attitude } \\
\hline Low risk tolerance & 0.010 & $(0.106)$ & 1707 \\
\hline Medium risk tolerance & 0.054 & $(0.104)$ & 2236 \\
\hline high risk tolerance & $0.287^{* *}$ & $(0.117)$ & 2432 \\
\hline \multicolumn{4}{|l|}{ education } \\
\hline university degree & $0.176^{\star *}$ & $(0.075)$ & 3895 \\
\hline \multicolumn{4}{|l|}{ industry exposure to the crisis } \\
\hline particularly affected & $0.325^{\star \star *}$ & $(0.075)$ & 3217 \\
\hline less affected & 0.056 & $(0.094)$ & 3024 \\
\hline \multicolumn{4}{|l|}{ application processing speed } \\
\hline fast (up to 5 days) & $0.158^{* *}$ & $(0.078)$ & 4541 \\
\hline $\begin{array}{l}\text { slow (more than } 5 \text { days) } \\
\text { elapsed time since granting }\end{array}$ & 0.044 & $(0.061)$ & 3057 \\
\hline up to 7 days & $0.329^{* * *}$ & $(0.074)$ & 1645 \\
\hline 15 to 21 days & 0.084 & $(0.070)$ & 2596 \\
\hline more than 21 days & 0.067 & $(0.069)$ & 2788 \\
\hline \multicolumn{4}{|c|}{$\begin{array}{l}\text { Notes: } p \text {-values: }{ }^{* * * *} p<0.01,{ }^{* *} 0.01<p<0.05,{ }^{*} 0.05<p<0.1 \text {. Standard } \\
\text { errors were bootstrapped with } B=1,999 \text { replications. The propensity score was } \\
\text { estimated with the Epanechnikov kernel matching algorithm applying the min- } \\
\text { max trimming criterion. The outcome variable is the subjective probability to stay } \\
\text { self-employed during the next } 12 \text { months coded as } 1 \text { ("very unlikely"), } 2 \text { ("likely"), } \\
3 \text { ("neutral"), } 4 \text { ("likely"), and } 5 \text { ("very likely"). }\end{array}$} \\
\hline
\end{tabular}

